Backcasting energy futures using industrial ecology

Dr Damien Giurco* (corresponding author)

Institute for Sustainable Futures; University of Technology, Sydney

P.O. Box 123

Broadway 2007

AUSTRALIA

*Damien.Giurco@uts.edu.au

Tel: +6129514 4978

Fax: +61 295144941

Dr Brett Cohen

The Green House

18 Kemms Road

Wynberg 7800

SOUTH AFRICA

Mr Edward Langham

Institute for Sustainable Futures; University of Technology, Sydney

P.O. Box 123

Broadway 2007

AUSTRALIA

Mr Matthew Warnken

WarnkenISE

P.O. Box 705

Glebe 2037

AUSTRALIA 


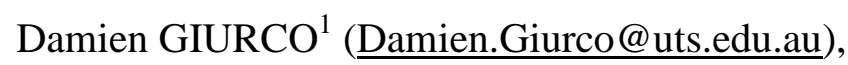

Brett COHEN ${ }^{2}$

Edward LANGHAM ${ }^{1}$

Matthew WARNKEN ${ }^{3}$

${ }^{1}$ Institute for Sustainable Futures, University of Technology Sydney (Australia)

${ }^{2}$ The Green House, Cape Town (South Africa)

${ }^{3}$ WarnkenISE, Glebe, Sydney (Australia)

\section{BACKCASTING ENERGY FUTURES USING INDUSTRIAL ECOLOGY}

Backcasting has been widely used for developing energy futures. This paper explores the potential for using industrial ecology to guide the development of energy futures within a backcasting framework. Building on the backcasting work of Robinson [1], a seven step method is presented to embed industrial ecology principles within the development and assessment of future scenarios and transition paths toward them. The approach is applied to the case of backcasting regional energy futures in the Latrobe Valley, near Melbourne, Australia. This region has substantial brown coal deposits which are currently mined and used in coal-fired power stations to generate electricity. Bounded by a sustainability vision for the region in a carbon-constrained world, regional industrial ecologies in 2050 were backcast around three themes: bioindustries and renewables (no coal usage); electricity from coal with carbon capture and storage (low to high coal usage); and coal to products such as hydrogen, ammonia, diesel, methanol, plastics and char (demonstrating medium to high overall coal use relative to current levels). Potential environmental, technological, sociopolitical and economic impacts of each scenario across various life cycle stages were characterised. Results offer a platform for regional policy development to underpin deliberation on a preferred future by the community, industry and other stakeholders. Industrial ecology principles were found to be useful in backcasting for creatively articulating alternative futures featuring industrial symbiosis. However, enabling the approach to guide implementation of sustainable transition pathways requires further development and would benefit from integration within the Strategic Sustainable Development framework of Robèrt and colleagues [2].

Keywords: coal; scenarios, regional futures; industrial ecology; life cycle assessment 


\section{INTRODUCTION}

Backcasting is an established approach to assess the feasibility and impacts of alternative futures [3, 4], with a focus on discovery, rather than justification [5]. Backcasting is also identified as a useful approach in the pursuit of sustainable development, within a five level hierarchy for a systems approach to Strategic Sustainable Development [2]. It does so by providing a strategic process (level 3) to meet the goal of sustainability (level 2) within the broader system (level 1); whilst also identifying specific actions for transition to sustainability (level 4) and using various tools and metrics to monitor progress (level 5). Korhonen [6] argues that Industrial Ecology can apply at all five levels of the Strategic Sustainable Development framework. With respect to the application of the industrial ecology metaphor at level 3 where backcasting is used, he offers a 'roundput' vision where waste materials, renewables and waste energy are used in cooperation. However, beyond this generalised vision, no examples were found explicitly using the principles of industrial ecology to guide the development of future scenarios in backcasting studies. Industrial ecology principles have been used in the planning of eco-industrial parks [7] and production (and consumption) systems [8, 9], but less so for regions, even though the potential for industrial ecology to inform cluster policy and regional development has been identified [10].

The aims of the study are to:

a) explore the potential of incorporating industrial ecology within a backcasting framework for developing regional energy futures;

b) develop a methodology to backcast regional industrial ecologies identifying potential barriers and opportunities for transition and an assessment of the benefits and environmental, technological, social and economic risk profile of each scenario across life cycle stages;

c) demonstrate the approach by way of a case study.

The case study chosen centres on the Latrobe Valley region in Victoria, Australia. The region contains large deposits of brown coal which are mined and burned in coal fired power stations, providing $85 \%$ of Victoria's electricity. Due to the strong dependence of the regional economy and society on coal, the region is vulnerable to 
policy directives related to carbon constraints. Although Carbon Capture and Storage (CCS) technology has been mooted as one solution to reducing the impact of such policy directives on local industry, it is recognised that a more diverse set of responses to the challenges is required to ensure ongoing prosperity in the region. The backcasting/industrial ecology approach is thus used to develop and explore such a diverse set of options towards building a more resilient future.

This paper is structured in five sections. Following this introduction, section 2 provides an overview of theories relating to both backcasting and industrial ecology, and the potential offered by using them in combination. Section 3 presents details of the backcasting methodology incorporating industrial ecology principles. Section 4 describes the application of the methodology to backcasting regional energy futures in the Latrobe Valley and discusses the results of the case study. Section 5 provides concluding reflections on the integration of industrial ecology within backcasting and promising areas for further research.

\section{BACKCASTING \& INDUSTRIAL ECOLOGY}

\subsection{Backcasting}

Backcasting is an approach to envisioning alternative futures which are discontinuous from the (often unsustainable) status quo, and to examining the transition path by which these alternative futures may be realised. Several authors have applied this approach in energy and sustainability related applications [11-14].

Dreborg [5] identifies five points for decision contexts where backcasting is most useful:

1. the problem is complex

2. there is a need for major change

3. dominant trends are part of the problem

4. externalities are important

5. the time horizon is long enough to allow for deliberate choice. 
Backcasting encourages a pro-active conceptualisation of the future, not merely based on what is currently in place, but also on what an alternative system could be that better meets desired goals. It begins with the perceived future need, rather than extrapolating current operations [15]. The positive aspect of backcasting is the assumption that the future can be designed through our action, while its weakness is that it may overstate the ability and will of actors to achieve these results [16].

Quist and Vergragt [17] outline three eras in the history of backcasting.

The first era, beginning in the 1970s, involved backcasting for energy, with a focus on the role of supply augmentation and demand reduction in meeting future needs [14, 18]. Evolutions of this approach, proposed by [14], considering supply-demand balance and options to both augment supply and reduce demand (rather than just increasing supply) have progressed to the establishment of Integrated Resources Planning (IRP) techniques for energy [19], and water [20, 21]. However, these no longer refer explicitly to backcasting. Interestingly, the common origin which the Lovins work [18] has provided to the now distinct fields of backcasting and integrated resources planning is not widely acknowledged.

The second era generalises insights relating to the backcasting process from applications in the energy sector and applies them to broader sustainability questions (see for example [1, 3, 5, 22]. This application emphasises the distinction between backcasting and forecasting, in that it allows a focus on desirable futures and the transition path by which they can be attained.

The third era, which has evolved over the last fifteen years, has been the development of participative backcasting, including broad stakeholder participation in generating future visions for moving beyond current paradigms [17, 23].

The approach taken in this paper is built on the early backcasting approach of Robinson [1], and explores societal choices by indicating the implications (including social and environmental) of different energy futures whilst remaining non-predictive. The rationale for this approach, was that the study would be used by government as an input to policy development and potentially broader engagement with stakeholders on SUBMITTED UNFORMATTED VERSION to Technological Forecasting and Social Change 2011 78:797-818 
developing a preferred future vision. There are two distinctive features of our work. First, we explore the potential for industrial ecology to be used in backcasting regional futures and to support transition paths toward alternative futures. Second, we propose that the alternative futures and poteintal transitions paths generated for each future scneario be used as an input to a broader participatory process to select a preferred future and transition path.

\subsection{Industrial Ecology}

Industrial ecology looks to the natural world for a model of what a more sustainable future may look like. It acknowledges that there are lessons for the way we run our industrial systems, based on the ecology of natural systems [24-26]. The metaphor of industrial ecology emphasises circular resource flows, which suggests that products and by-products should be reused, repaired, recovered, remanufactured or recycled. It finds application from the scale of eco-industrial parks to the economy as a whole. Lifset and Graedel [27] outline six of the core elements of the field of industrial ecology:

- the biological analogy;

- the use of systems perspectives;

- the role of technological change;

- the role of companies;

- dematerialisation and eco-efficiency

- forward looking research and practice.

When applying industrial ecology, two approaches feature heavily: the 'productbased systems approach’ and the 'geographical systems approach’ [28, 29]. The 'product-based systems approach' focuses on the impacts of a product, taking into consideration all processes along its life cycle from raw material extraction to disposal. This also links with the Life Cycle Assessment (LCA) literature (see for example [30, 31]). The approach seeks to trace and measure the material as well as the energy inputs and outputs related to firms, processes, products, materials and / or substances, associated with the production of a product. The approach provides information that can inform both operational management and policy development. 
The 'geographical systems approach' that is used to develop scenarios within the backcasting process later in this paper, explores the way in which a collection of industrial actors in a geographically defined area may act together to form an industrial ecosystem [32]. Such an ecosystem is the product of "co-operation and interdependency, they use each other's waste material (recycling of matter) and waste energy (cascading of energy) to substitute for resources” [28]. The geographical systems approach often described in relation to Eco-industrial Parks (EIPs) and regions [33] [34-36]. In addition to sharing material and energy flows between firms, the literature identifies that the clustering of businesses to achieve primarily environmental, but also economic and social, benefits [37].

Industrial symbiosis is a subset of industrial ecology and defined by Chertow thus: "Industrial symbiosis engages traditionally separate industries in a collective approach to competitive advantage involving physical exchange of materials, energy, water, and/or by-products. The keys to industrial symbiosis are collaboration and the synergistic possibilities offered by geographic proximity” [38]. Localised industrial ecology in the form of industrial symbiosis could also have the broader benefit of linking to regional development [10]. Industrial symbiosis may otherwise be defined as: "A co-operation between different industries by which the presence of each of them increases the viability of the others and by which the demands from society for resource conservation and environmental protection are taken into consideration.” [39]

This paper seeks to explore the potential role that industrial ecology can play within a backcasting framework, guiding the development of alternative futures using a systems perspective and the biological analogy. With a focus on the sharing of knowledge and resources, it further considers the potential for industrial symbiosis to strengthen the competitive advantage and viability of transitions toward future scenarios in regions which are renewing their industry base with a focus on dematerialization and eco-efficiency. 


\subsection{Linking industrial ecology and backcasting}

Combining industrial ecology and backcasting has the potential to focus development on a new, more sustainable business base for a region [10, 40,41] or city [42]. However, no previous case studies were found where industrial ecology principles were explicitly used in backcasting regional energy futures. This section now discusses the points that were considered in the context of linking industrial ecology and backcasting.

\subsubsection{Considerations relating to promotion of cyclical resource flows}

An explicit focus on industrial ecology in backcasting can promote the potential of closed loop resource cycles in visions of the future, or principles for the constitution of the system [6]. Here the system is as defined in the five level Strategic Sustainable Development framework [2], as discussed in section 1 above. Some authors see a role for experts in proposing the future in a more structured way [43] while others do not seek to formalise the creative process of imagining more preferred future scenarios as 'getting ideas' is a non-logical process [5]. Our proposed use of industrial ecology for backcasting is a hybrid position - drawing inspiration from the potential offered by industrial ecology when developing alternative futures, without mandating too rigid a structure for doing so, thus recognising that good ideas may also arise from less structured processes. Whilst it could be argued that promoting industrial ecology in future scenarios introduces an inherently normative component (for example, over scenarios based on a linear economy), if the pursuit of industrial ecology-based scenarios is applied outside the Strategic Sustainable Development framework, such futures may not necessarily be sustainable [6]. This is discussed further in 2.3.4.

When considering the use of industrial ecology in backcasting for promotion of cyclical resource flows, three alternatives can be considered:

i. new patterns of resource and energy flows based on industrial ecology principles;

ii. new technologies to enable more efficiency use of resources and energy largely within existing system configurations;

iii. new technologies and new patterns of resource and energy use within the system. 
Each permutation reflects a different emphasis of the elements of industrial ecology identified earlier [27]. Whilst all draw on the biological analogy and a systems perspective, the role of companies, technology and dematerialisation will vary in (i), (ii) and (iii).

This paper focuses on using industrial ecology to guide system configurations incorporating proven or developing technology, rather than populating scenarios mainly with unproven technological ideas in new patterns of resource and energy flows. The approach of using predominantly available technology seeks to strengthen stakeholder buy-in by creating futures scenarios that may be considered more realistic or tangible.

\subsubsection{Considerations relating to geographic and product focus}

When considering the potential for improved flow of knowledge, resources and symbiosis within a product focus, this will need to address suppliers, customers (and possibly competitors) along the product's supply chain. In a regional focus, the knowledge sharing and integration is more likely to occur across completely different industry sectors.

When considering industrial ecology with a geographic focus, it is important to consider the scale at which the analysis is being conducted - eco-industrial park, region, nation or world. The scale of analysis determines the exogenous variables to be considered [1], as well as dominant actors and stakeholders.

\subsubsection{Considerations relating to industrial symbiosis, clusters and transitions}

The role of clusters in the competitiveness and prosperity of nations internationally was highlighted by Porter [44] and the history and experiences associated with clusters in Australia is well reviewed by Roberts and Enright [45].

Whilst all clusters need not have an environmental focus, those set up as EcoIndustrial Parks, based on industrial symbiosis, specifically promote environmental benefits of resource and information sharing at a localised site (see [38, 46, 47]). 
These often include large companies with a focus on physical resource-sharing and utility-sharing. However, clusters may also constitute small and medium sized enterprises (SMEs) which develop through knowledge-sharing and innovation. They tend to be dynamic and adaptable as ideas spread through the cluster quickly and the size of the organisations allows them to adjust more quickly than larger, more unwieldy companies. These attributes can be viewed as strengths when considering the transition path to an alternative future arising from backcasting, where the future industry base is substantially different.

A review of international industrial ecology or "regional synergy" case studies by van Berkel [48] indicated that there are three further factors influencing success:

- technology must be proven, well-developed and viable

- the business case must be convincing and ensure financial returns

- broad stakeholder consensus supporting the synergies should provide the 'licence to operate'.

These insights support the focus in this work on system innovation and configuration of resource flows and interconnections, rather than on incorporation of new, unproved technologies. It was felt that both inclusion of radically new technologies and implementation of new system configurations at the same time would further increase the risks (or transition hurdles).

\subsubsection{Risks and challenges of the approach}

Korhonen [6] identifies the following four risks when industrial ecology principles are applied outside of a broader sustainable development context such as the Strategic Sustainable Development framework (SSD) developed by Robèrt et al [2]:

1. Industrial ecology approaches often give rise to promotion of eco-efficiency, where a product is manufactured more efficiently, with lower resources, energy and/or wastes. It can also support substitution of one material in the supply chain with another. For example, an industrial ecology relationship which encourages waste heat use from a coal fired power plant still relies on fossil fuel, while replacing virgin paper with recycled paper does not encourage a move away from paper use per se. Both of these may give rise to seemingly positive short term gains, but ultimately represent problem shifting 
which is sub-optimal in terms of sustainability, including the rebound effect [49].

2. The SSD framework considers not only material and energy flows, but also cultural, social, economic and human dimensions of sustainability. Industrial ecology has the potential to address both elements of the model (through consideration of physical flows of material and energy as well as the broader natural ecosystem metaphor). There is, however, a risk within the industrial ecology framework in considering physical flows without addressing cooperation, community culture and other non material and energy factors.

3. Differing views on preferred policy and management approaches may be obtained when comparing the results from the industrial ecology approaches to those of Life Cycle Assessment or the requirements of an Environmental Management System for an individual company. Use of one or more of these tools in isolation may thus provide outcomes which are not in line with the overall objectives. The authors of the SSD suggest the use of a variety of tools in a complementary fashion in order to contribute to meeting the overall aims.

4. Korhonen identifies the concept of "Flexible platforms" to be used as a principle for investment decisions in the Framework. Here, investments that are made now are considered both for their potential to solve current 'acute' problems, and as stepping stones for future investments according to the vision of the future. A situation may occur in which such investments result in suboptimal solutions in the short term. These opportunities may be missed if using industrial ecology outside of the Framework, and investment decisions may be made which result in short term gain but long term lock-in to less sustainable options.

Such risks are also present when using industrial ecology within a backcasting framework. The importance of flexible platforms in particular is relevant for considering transition pathways to alternative futures. The backcasting study described in this paper was not embedded within the Strategic Sustainable Development framework due to resource constraints. It is discussed above to highlight the potential limitations of our work and to guide future research. 


\section{METHODOLOGY}

The generic steps involved in backcasting are to specify goals and objectives within the context of the future operating environment in order to formulate a range of futures or scenarios [43] [3], and to identify the changes that would need to be made to the current system to realise these futures (transition pathways). The approach taken in this research has common elements with the generic backcasting methodology developed by Robinson [1]. That is, a range of alternative possible futures are explored which are "oriented towards testing the feasibility and impacts of such futures”, to aid in the decision making processes to determine policy direction [1].

An overview of the methodology applied to combine an industrial ecology approach within Robinson's broader framework of backcasting a series of alternative future scenarios is shown in Figure 1. The seven stages in the methodology are discussed below.

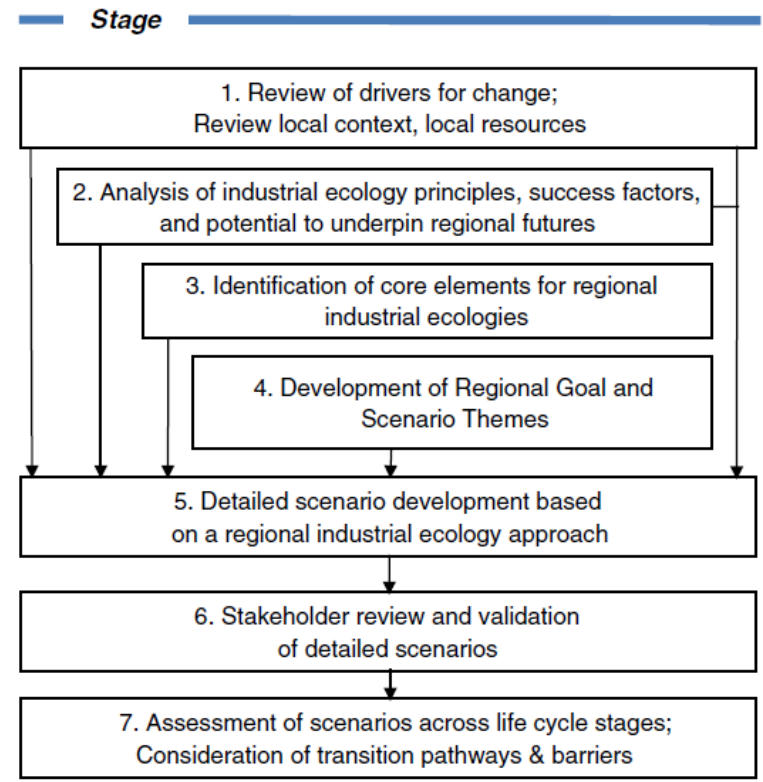

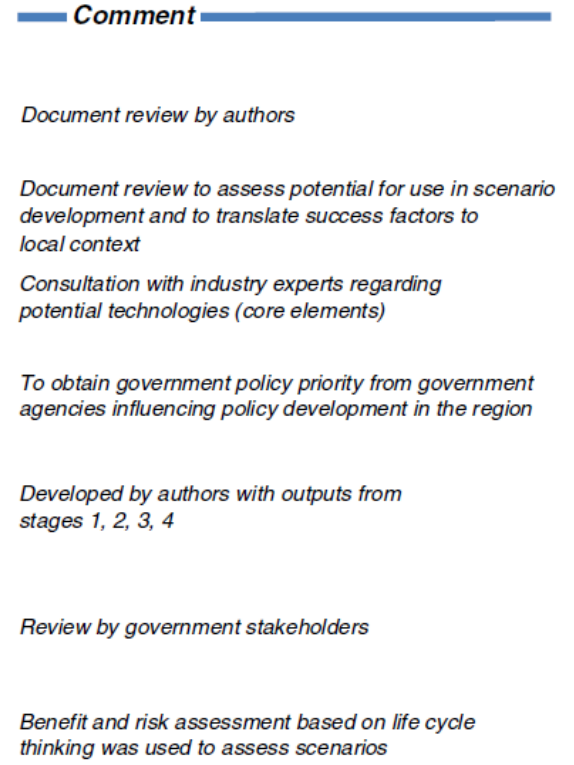

thinking was used to assess scenarios

\section{Figure 1: Overview of process}

\subsection{Stage 1: Review of drivers, local context and resources}

The process began with a review of current and expected drivers of change in the region of study. This review was performed in parallel with assessments of the local socio-political context and the available natural, economic and social capital. These 
elements comprise the "human activities side of an integrated approach to analysing the relationships between humans and the environment”, as described by Robinson [1].

Drivers for change included environmental, socio-political and other major factors that were considered likely to shape the operating environment or nature of future industries in the region to 2050. The most significant driver identified was the imposition of an economy-wide carbon constraint, which was considered over the time horizon to require the reduction of greenhouse gas emissions to near zero levels. The analysis extended to the assessment of the impacts of a carbon constraint on the range of economic sectors and industries in the region.

Research of the local context included historical developments in the region that have been influential in shaping public perceptions of local industries, an analysis of population trends and the current employment situation, and major development plans in place through planning instruments or other local government documents.

The local resource assessment was a systematic process of examining the available human resources (the skills base in the labour force), renewable and non-renewable natural resources and environmental constraints, and the economic situation influencing development in the short to medium term.

This stage formed the foundation for the research and an important point of reference for later analysis of the barriers involved in the transition to the range of identified scenarios (Stage 6).

\subsection{Stage 2: Industrial Ecology Principles and Potential}

The second stage was to analyse historical industrial ecology theory and applications both in Australia and internationally [47, 50-54]. This allowed identification of not only the potential industrial ecology linkages for use in development of scenarios, but also of lessons regarding successes and failures of industrial ecology projects. Key considerations influencing the success of the case studies were extracted and interpreted in the light of the local situation within the study region, as established in Stage 1.

\subsection{Stage 3: Identification of Core Cluster Elements}


Stage 3 identified individual core elements (in other words, building blocks, such as technologies or processes) that could be used to develop the scenarios. Currently available and future technologies were identified over the time horizon to 2050, with a focus on the dominant 'core industries' already at the centre of employment and primary productivity in the region. As coal and energy products are the current industrial focus, the suite of core elements of industrial clusters were developed around i) coal and its derivatives, ii) non-coal energy elements and iii) non-coal, nonenergy elements.

\subsection{Stage 4: Development of Regional Goal and Scenario Themes}

Before developing scenarios and transition paths, the relevant government agencies involved in policy development affecting the broader region were gathered in a workshop to establish a regional goal and scenario themes. This is akin to Robinson's "statement of purpose” [1]. The long-term "regional goal” was formalised to provide a framework to guide the development of the scenarios, with the requirement that every scenario would aim to ensure that the regional goal was realised. Three intentionally distinct scenario "themes" were then established with the government stakeholders, which loosely defined the industry focus in each scenario. Establishing these diverse themes allowed the creation of three alternative futures - each with underlying differences in the values and interests they embody - to be developed using industrial ecology principles.

\subsection{Stage 5: Scenario Development}

The scenarios developed in this paper explore a breadth of alternative futures that could arise from differing combinations of drivers (both local and global), which in turn, have implications for how coal is utilised in the scenario. The motivation behind describing divergent future scenarios in this work is to analyse the similarities and differences in the business sectors and technologies that appear in each scenario, and to use the assessment of the different environmental impacts across life cycle stages to better understand the strengths and weaknesses of each option.

Three alternative future scenarios were created around the structure of industrial clusters in 2050. The long-term time horizon of the backcasting exercise allows the existing strengths of the region to be built upon, but is far enough in the future to not be dominated by them. The scenarios were designed with minimal overlap, with each 
scenario conforming to one of the themes developed in Stage 4. The distinct themes allowed the scenarios to be constructed to "test the feasibility and impacts" of a range of alternative possible futures, as per Robinson's methodology [1]. In actuality, blended or hybridised forms of the scenarios are equally plausible. Although the scenarios were developed to all fall within the regional goal, no scenario was prejudged as either more likely or more desirable than another.

Each scenario was constructed by bringing together within an industrial symbiosis, the core industrial and technological elements identified in Stage 3, with consideration of the local resources, strengths and constraints from Stage 1, and success factors from Stage 2. In other words, the elements from the previous 4 stages of the analysis were combined qualitatively by the research team into textual descriptions of the key elements of the scenario in question. Industrial ecology inspired synergies between those core elements were then established with regard to the material, human and economic inputs and outputs associated with each industry/technology. The conceptual inputs to the scenario development are illustrated in Figure 2.

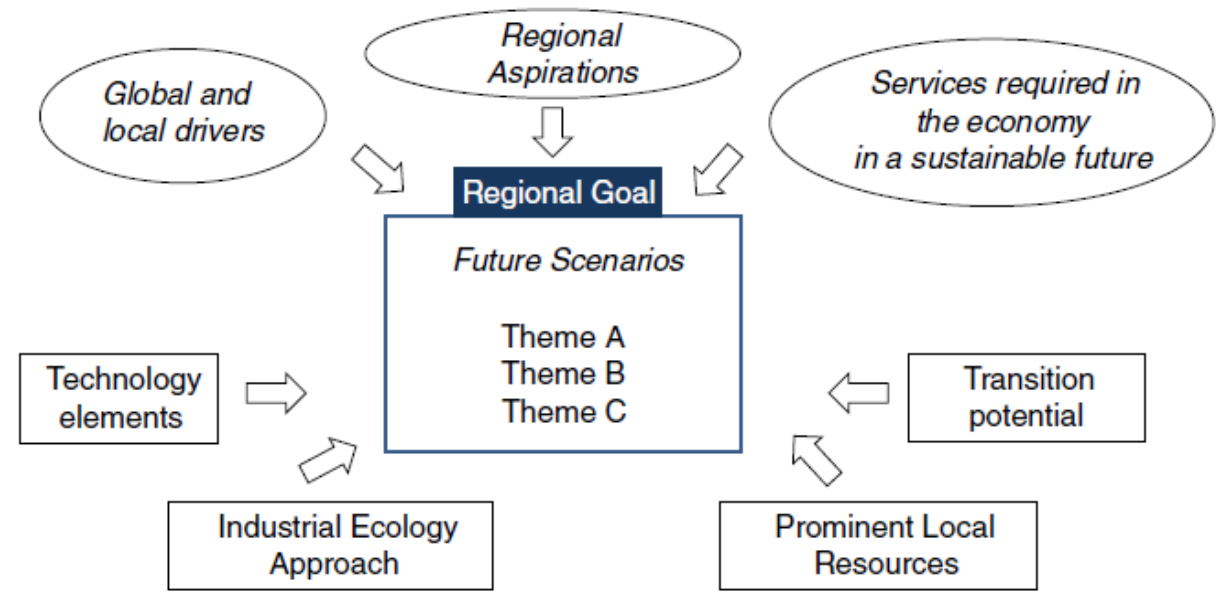

Figure 2: Conceptual inputs to backcasting scenarios

\subsection{Stage 6: Stakeholder Review and Validation}

The results of Stages 1 to 6 were validated by a reference group of government stakeholders to ensure that the scenarios were considered compatible with the regional goal, were sufficiently shaped by the overarching drivers and constraints, and suitably represented the diversity of future options for policy discussion regarding employment and industry structure in the region in 2050. Involving policy-makers in 
this way promoted greater engagement with the research process and outcomes . The stakeholder reference group also channelled feedback from a wider group of departmental staff and resulted in new core elements being added to scenarios, such as waste heat and $\mathrm{CO}_{2}$ being used as in input to fish farming and greenhouses for growing tomatoes.

\subsection{Stage 7: Scenario Impact Assessment and Transition Pathways}

In developing the approach to be used in the assessment of scenarios, various alternatives were considered. The first of these, Life Cycle Assessment (LCA) has been identified as having a useful role to play in assessment of scenarios [55, 56]. LCAs are typically very data intensive, with the level of information detail included depending on the uncertainty associated with the scenarios being assessed and the objective of the assessment. Streamlined Life Cycle Assessment (SLCA), which essentially refers to LCA studies requiring less detailed levels of information, was also considered [57]. Despite LCA and SLCA approaches being used by others in scenario analysis, a significant complication of seeking to apply formal LCA processes in this study was that there was no common 'functional unit' between the scenarios. Some scenarios primarily produce energy, some produce primarily products, and some produce both, and at varying scales. This observation, coupled with a very low level of data availability for the future scenarios, led to LCA and SLCA approaches being rejected.

Sustainability assessment (see, for example, [58]) refers to an alternative set of approaches to evaluation of policies, plans and processes, used for more strategic assessments which have lower levels of information availability. Sustainability assessment is related to impact assessment processes such as Environmental Impact Assessment (EIA) (e.g. [59, 60]) and Strategic Environmental Assessment (SEA) (for example [60] in the energy sector and [61, 62] as applied to policies, plans and programmes (PPPs)). "Sustainability appraisal” and "integrated assessment” fall into a similar group of approaches, and allow for simultaneous assessment of the environmental, social and economic impacts of actions and decisions [63]. Unlike LCA and SLCA, such assessments typically use semi-quantitative and qualitative data 
for analysis (see for example [20]). Using this level of information detail is seen as advantageous and by not providing a numerical 'score', it keeps perceptions regarding the level of uncertainty of impact classification more consistent with the level of uncertainty of input information.

The approach used in this current work for scenario assessment is broadly based on the sustainability assessment-type approaches such as that used by Nijkamp and Vreeker [64], with a focus on semi-quantitative assessment of energy and water impacts and qualitative assessments of technical, socio-political and economic challenges. This methodology applied in this study differed, however, by conducting sustainability assessments using a life cycle thinking perspective. This implies that the whole value chain is considered in the analysis, including impacts at the life cycle stages of mining/raw material inputs, production/ processing and use/disposal.

The remaining important step of the backcasting process was to consider the changes from the current situation required to realise each of these futures. This step is known as the establishment of "transition pathways" or more flexible "migration pathways" [65], while Robinson [1] refers to establishing conditions at mid-points on the way to the end-point. This process is important in establishing the barriers to achieving transition to a future scenario, given current conditions and local constraints. Critical to this assessment is the consideration of the gap between the existing and required skills and knowledge base in the labour force, as well as natural resource and other environmental constraints. This research placed less of a focus on working through detailed decade-by-decade transition pathways, but rather highlighted significant transitionary considerations in an integrated way through the impact analysis.

The next section outlines the regional case study of Latrobe Valley in the state of Victoria, Australia, to which this backcasting methodology was applied. 


\section{CASE STUDY ON ENERGY FUTURES: LATROBE VALLEY, AUSTRALIA}

\subsection{Background}

The Latrobe Valley is situated in the State of Victoria (Australia), 150km southwest of Melbourne, a city with four million inhabitants. The region has substantial brown coal deposits which are currently mined for use in coal-fired power stations, supplying 85\% of Victoria’s electricity [66], with most of the remainder coming from natural gas. Policy directives responding to carbon-constrained futures will thus impact directly on this region, with one of the main proposed solutions involving large commercial scale carbon capture and geological storage for coal-based Latrobe Valley industries. However, it has been recognised that a more integrated, diverse and creative response to the climate change challenge is pivotal to the area's long term prosperity.

The Latrobe Valley has already benefited from a Victorian Government strategy to promote the region as an industrial and resource processing hub and thus diversify away from being solely dependant on the coal sector. The Latrobe Economic Development Strategy 2004-2008 [67] notes that the future of Latrobe will rely heavily on innovation- and knowledge-based organisations to support its existing leading sectors. Other coal-intensive regions in Australia such as the Hunter Valley in New South Wales are also considering their future dependency on coal and have begun developing strategies for a lower carbon future with a focus on a fair and just transition [68].

It is within this context that the research presented in this paper was commissioned by the Victorian Department of Primary Industries (Australia).

\subsection{Stage 1: Drivers, local context and resources}

\subsubsection{Drivers: current and future}

The challenge of climate change has prompted several responses at both the national and state government level in Australia. At the national level, the Australian Government has committed on the international stage to an unconditional 5\% reduction in carbon emissions from 2000 levels by 2020, increasing to 25\% with greater levels of ambition from the global community. The longer term policy commitment is for $60 \%$ reduction from 2000 levels by 2050. Irrespective of the 
ongoing debate over the stringency or adequacy of these targets, the trend in moving towards 2050 (the timeframe of this analysis) is for dramatic reductions in emissions, ultimately approaching zero. As part of the proposed (but at the time of writing, postponed) emissions trading scheme, compensation plans (including free permits) for emission-intensive trade-exposed sectors were a major feature. Coal exports were included in the compensation plans, but not coal fired electricity for which a separate compensatory scheme was proposed. At the same time, the Victorian (state) Government - which currently relies heavily on coal-based electricity generation has also committed to reducing emissions by $60 \%$ by 2050, based on 2000 levels.

Further drivers of change identified include constraints on water resources [69], the potential for hydrogen and methanol utilisation in economy [70], the role of distributed versus centralised energy in Australia [71, 72] and new societal norms including work habits [73]. Additionally, we can reasonably expect there to be disruptive technologies adopted which are not currently foreseen and which will alter future drivers for industrial ecology and sustainability.

\subsubsection{Industrial context}

The Latrobe Valley experienced a significant economic shock in the early 1990s, leading to unemployment levels of $12 \%$ [74] and a dramatic increase in the migration of people out of the area in search of work. However, the recent Victorian Government strategy to promote the Latrobe Valley as an industrial and resource processing hub for Victoria has seen growth in employment in sectors such as manufacturing, property and business services, retailing and other service sectors that are less reliant on the energy sector [75].

According to The Latrobe City Economic Development Strategy 2004-2008 [67] and Latrobe 2021 [66], the region’s competitive strengths are:

- energy

- forestry, timber and paper

- food and agribusiness

- advanced manufacturing and aviation

- $\quad$ services, tourism and events 
- tertiary education.

The Strategy also notes that a focus for the future of Latrobe will be on 'new and emerging businesses', which are defined as innovation- and knowledge-based companies. Latrobe City [66] notes that multi-million dollar investments are being planned to increase electricity generating capacity and support the region's engineering and manufacturing firms. This provides opportunities for businesses to locate close to the generators and connect to them directly for cheaper power prices. Although mining only provides $1 \%$ of jobs, the manufacturing industry - driven by cheap coal-fired electricity - employs a further $12 \%$ of people and is the second biggest employer by sector.

\subsubsection{Social context}

In a traditional sense, Latrobe's labour force is relatively less skilled at the tertiary level than the Victorian labour force as a whole, with half as many people having completed a university degree [75]. However, more people have vocational 'certificate’ qualifications through Technical And Further Education (TAFE) and adult education centres, suggesting strengths in the trades and associated industries.

Additionally, many of Latrobe’s workers without formal qualifications will have developed skills specific to the industry within which they are employed. Thus in this analysis it will be necessary to examine the skills that are developed by workers in the coal industry to evaluate how these skills could be utilised in future transitions to sustainable industry in the region.

Skill levels have also been used to indicate social well-being. More skilled communities are considered more flexible in their ability to pursue alternative job opportunities in the event of changes or downturns in a specific industry [74]. Widespread changes in the coal industry could affect the number and types of jobs available and force extensive re-training of the workforce. 


\subsubsection{Available natural resources and constraints}

The dominant resource available in the Latrobe Valley is brown coal, which is combusted to produce the majority of Victoria's baseload electricity [66]. Known reserves could meet Victoria’s energy needs for hundreds of years. However, a number of other natural resources are also found in the valley or nearby:

- forest products

- geothermal energy potential (Gippsland Basin and possibly Latrobe Valley)

- natural gas (readily available from the Gippsland Basin)

- ash

- saline water.

As long coal combustion continues in the region, local resources for consideration also include the by-products of coal burning: methane $\left(\mathrm{CH}_{4}\right)$; carbon dioxide $\left(\mathrm{CO}_{2}\right)$ and oxides of nitrogen and sulphur (NOx, SOx). ${ }^{1}$

Fresh water has also been identified as a valuable natural resource. However, while the Latrobe Valley has a more secure water supply and a waste system with larger capacity than any other Victorian region [66], the competing water requirements of both Melbourne and the Latrobe Valley power stations will ensure that water supply will be a constraint into the future. Water shortage impacts on power generation have already been observed, with wholesale electricity prices increasing due to droughtinduced water supply shortages for coal fired power stations [76]. Water quality within the Latrobe River varies greatly but the condition of the overall Latrobe River has been rated as 'poor' [66].

\subsection{Stage 2: Application of industrial ecology in Latrobe Valley}

A review of selected international industrial ecology cases is presented in Table 1 in order to identify lessons relevant to both to backcasting and to implementing future scenarios for the Latrobe Valley.

\footnotetext{
${ }^{1}$ Whilst these pollutants are commonly considered wastes, we have sought to include them here, consistent with an industrial ecology based approach. 
Table 1: Application of industrial ecology insights to Latrobe Valley context Key points for each case study

Kwinana case study[53]

- Large scale of development Relevance to Latrobe Valley

- Large-scale area and industries mean greater potential to share resources and gain major efficiencies

- Coordinated by Industry Council, address issues and foster relationships

- Precinct evolved over time

- Diverse industries are present in industrial cluster

- Should be a focus for Latrobe

- Long-term political and industry commitment is required

- Latrobe is starting from a narrower industrial base, but opportunities exist for expansion of other industries (e.g. forestry, agriculture). Reliance on one industry is both a risk and an opportunity, in becoming a centre for innovation around coal products/technologies

- Co-operation between public and private organisations has proven valuable

- A co-ordinating body could facilitate similar cooperation

- Obtaining a 'social license to operate' important for success

- This is important for Latrobe and further and diverse opportunities must be pursued for two-way communication with stakeholders

Kalundborg case study [54, 44]

- Centralised, with a power station providing the focal point

- Public and private organisations collaborate

- Addresses water scarcity. The park has decreased groundwater consumption by $90 \%$
- Could focus development around coal mining and processing, or around innovation in new renewable or CCS technologies

- A co-ordinating body could facilitate similar cooperation

- Collaboration between industry clusters could also address this issue already affecting the Latrobe Valley
Styria case study [85]

- Significant recycling of waste materials

- Diverse industries present in cluster

- 'Evolutionary’ (less planned) origins

- Businesses generate revenue through sale of waste streams

- Complex

- No inter-company organisation
- Huge opportunities exist for the Latrobe Valley to recycle waste materials, water, etc.

- Could investigate opportunities for industry diversification, for example in knowledgeand innovation-based industries.

- Concerted effort to plan \& develop clusters in Latrobe could improve synergies

- Latrobe can investigate opportunities for productive use of waste streams, including carbon dioxide, to boost profitability

- Potentially complex systems. Much depends on which scenario/cluster elements are pursued

- The planning necessary to develop clusters in Latrobe will require a co-ordinating body

*Further industrial ecology case studies are reviewed in [77]. 
The development of regional industrial ecologies offers numerous potential benefits for the Latrobe Valley, particularly the opportunity to develop a more secure water supply in the face of ongoing shortages. Heeres and co-authors [78] noted that the most successful eco-industrial parks begin with utility sharing, or regional collaborations in response to water or energy scarcity. Given the water shortage affecting the Latrobe Valley, this could provide an appropriate acute stimulus for the area to develop its own industrial ecology, in addition to ongoing need to achieve carbon emissions reductions.

If the Latrobe Valley were to follow the Kalundborg model of having an anchor tenant it would benefit from utilising existing infrastructure. However, reliance on one anchor member (often known as a ‘hub-and-spoke’ arrangement) can also present risks, for example, if that industry collapses or organisation fails.

\subsection{Stage 3: Identification of the core elements for regional industrial ecologies}

A comprehensive description of the core elements used in the future cluster development is presented in Giurco et al. [77]. A summary is provided in Table 2, although not all elements were utilised in further development of scenarios, and other elements not on this list were ultimately included in the scenarios.

Table 2: Core elements for industrial clusters

\begin{tabular}{ll}
\hline Cluster Element & Comment \\
\hline Coal elements (and derivatives) & \\
Potential for coal for export & Coal use currently for local power generation \\
Syngas/Hydrogen via gassification & Technology available, not widely applied \\
Liquid fuels via Fisher Tropsch & Technology available, applied in South Africa \\
Direct liquefaction of brown coal & High pressure/temperature; technically feasible \\
Methanol and derivatives & Significant potential use of brown coal \\
Ammonia and derivatives & Uses hydrogen from gasification as feed \\
Char production via pyrolysis & For use as metallurgical reductant \\
Convert brown to black coal & Technology under development \\
Carbon nanotubes & Technology under development \\
Carbon capture and storage & Pilot projects being developed (e.g. Otways) \\
Carbon dioxide to chemicals: polymers, & Technology under development \\
methane, acetic acid & \\
Non-coal energy elements & \\
Syngas/Hydrogen from biomass & Technology available (e.g. Lahti, Finland) \\
Biomass pyrolysis to oil/gas/char & Technology under development
\end{tabular}


Biomass from algae

Liquid biofuels

Geothermal energy

Solar energy

Wind energy

Non-coal, non-energy elements

Magnesium production from ash

Brown coal for steel making

Geopolymer production

$\mathrm{CO} 2$ for horticulture

Aquaculture

Urban waste cycling
Trial underway in Latrobe Valley (e.g. MDB)

Technology available

Technology under development

Technology available \& further developing

Technology available

Technology under development

Technology under development

Technology under trial

Technology available

Low grade heat in mine sites for growing algae Technology available

\subsection{Stage 4: Developing a regional goal and scenario themes}

\subsubsection{Guiding principles for a regional goal}

Boundaries were set for the scenario development by developing a regional goal around which the scenarios were constructed. Consequently, whilst the development of alternative futures will have varying social and environmental impacts, they have an implicit normative element due to conformity with the regional goal.

To assist in defining the goal, the following guiding principles were gleaned from the common elements of the strategy documents and state government policies relating to the Latrobe Valley reviewed in [77]:

\section{Environmental}

- the future will be carbon constrained and Victoria and the Latrobe Valley will each have their roles in reducing greenhouse gas emissions. To the Victorian Government, brown coal is seen as a desirable part of that future because i) it is a key part of the current Latrobe Valley economy, and ii) it provides cheap, reliable electricity and thereby competitive advantage to manufacturing industries in the region. However, this position is highly contested both locally and globally, and it is recognised by both government and industry that a prosperous future for coal can only be realised if 'clean coal' processes, including carbon capture and storage, are able to be developed quickly and effectively. Thus, there is significant investment and expectation riding on these technological solutions. The authors do not seek to advance a particular position in this work, but rather aim to ensure that the breadth of future scenarios considered do not all carry this contested technological risk. 
- water use by the power generation and mining sectors will also need to be improved as energy sources and industries which are less water-intensive will gain competitive advantage.

- there will be an increasing focus on reducing waste, particularly in the mineral resources sector.

- nuclear power is not currently under consideration by the Victorian Government.

\section{Economic}

- growth in both population and economy should underpin the long term future of the Latrobe Valley. It is envisaged that the industry's current strengths that are focused on energy will continue to grow into the future and further develop the skills sets of the region.

\section{Social}

- the Latrobe Valley will be a growing, harmonious, prosperous and sustainable region based on the principle of social equity. Community leadership and advocacy is envisaged to play a greater role in the future, with residents actively driving, and responding to, social and community issues.

The above principles provided direct input to the development of the following regional goal for the Latrobe Valley:

In a carbon-constrained and water-constrained world, the Latrobe Valley will achieve environmental sustainability in a zero-emissions future, while maintaining social and economic growth in a vibrant, diverse and caring community.

The goal was developed by the authors together with selected government agencies and provides an overarching framework for the scenarios themselves. It is intended to expand rather than narrow consideration of what could be possible in the Latrobe Valley. From a methodological perspective, this may be better termed an interim vision, developed with expert stakeholders to frame the backcasting for policy 
development. Whilst it was not possible within the constraints of this work, it is proposed that such an interim vision be further developed with citizens (in addition to expert stakeholders) as a precedent to agreeing on a preferred future through more participatory processes.

\subsubsection{Scenario themes}

The three distinctive scenario themes were defined by the following characteristics and potential drivers:

- Scenario theme A: Bio-industry \& renewables focus

Rapid behaviour change, swift action to avert climate change, backlash against coal/CCS, alternative energy cost-competitive, lack of water, communities seek local self-sufficiency in energy.

- Scenario theme B: Electricity from coal focus

Business as usual with technology - in particular CCS - negating the greenhouse impact problems associated with the utilisation of coal for power generation.

- Scenario theme C: Products from coal focus

Resource constraints (in oil / water) lead to upheaval and innovation in new areas with a focus on uses for coal beyond electricity generation.

Each of the three proposed scenarios follows a different guiding theme. While Scenarios A and B are centred around the Latrobe Valley as an energy hub, Scenario C positions the region as a coal producer outside of electricity supply.

More detailed descriptions of the three scenarios are presented in the next section.

\subsection{Stage 5: Future Scenario Development}

An overview of the key components of each scenario is given in Figure 2. 
Figure 2 - Overview of drivers, cluster elements and coal utilisation for each scenario

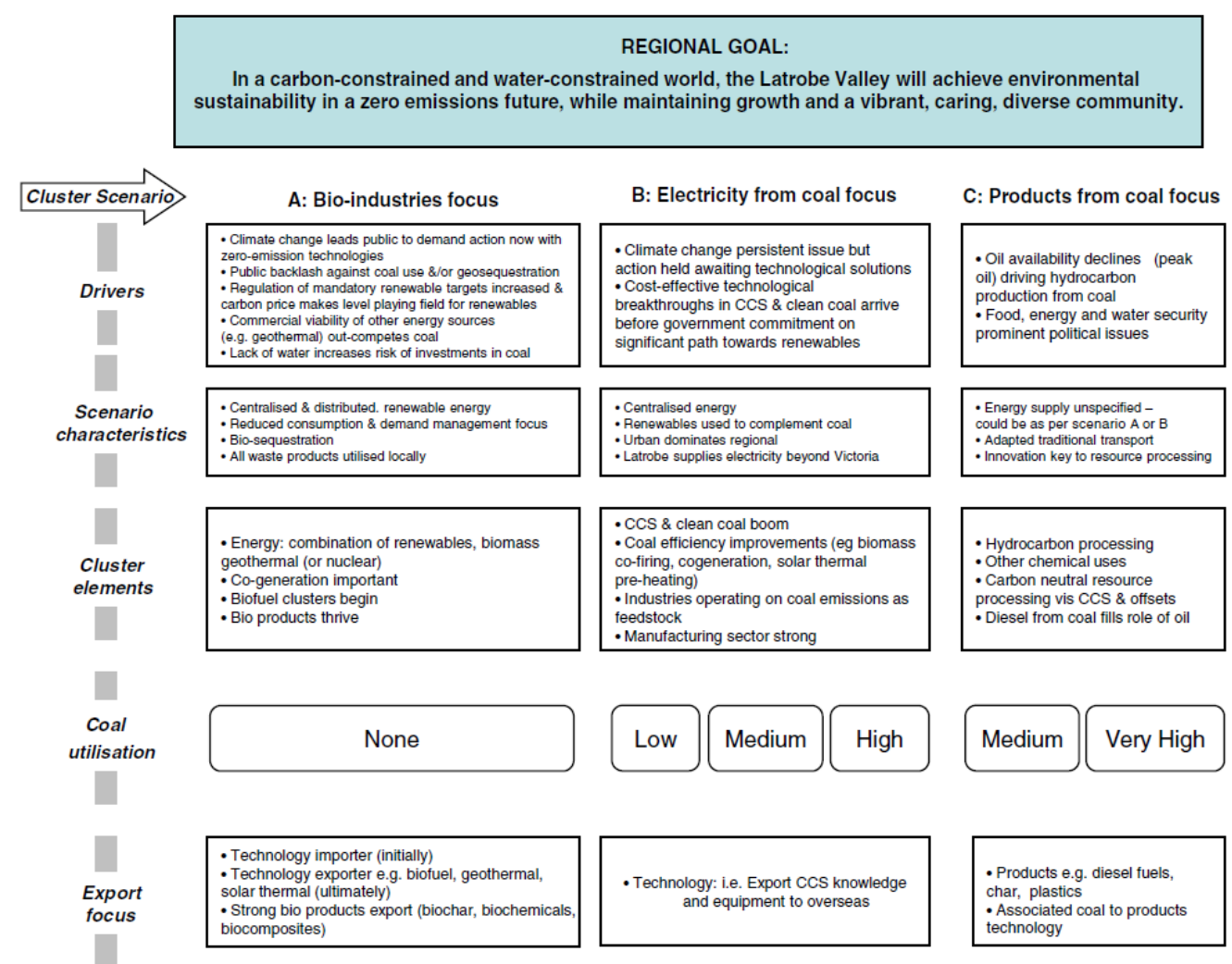

Each scenario was developed by selecting core cluster elements which fit within the scenario theme and arranging them in a system configuration which builds on industrial ecology principles. No numerical modelling of material or energy flows was performed due to the data requirements and level of detail required at this conceptual stage of the process. The three scenarios are now described in further detail, while the transitionary considerations are discussed in Section 4.8.

\subsubsection{Scenario A - Bio-industry \& Renewables Focus}

The configuration of cluster elements in Scenario A is given in Figure 3. 
Figure 3 - Configuration of Scenario A: Bio-industry \& Renewables focus

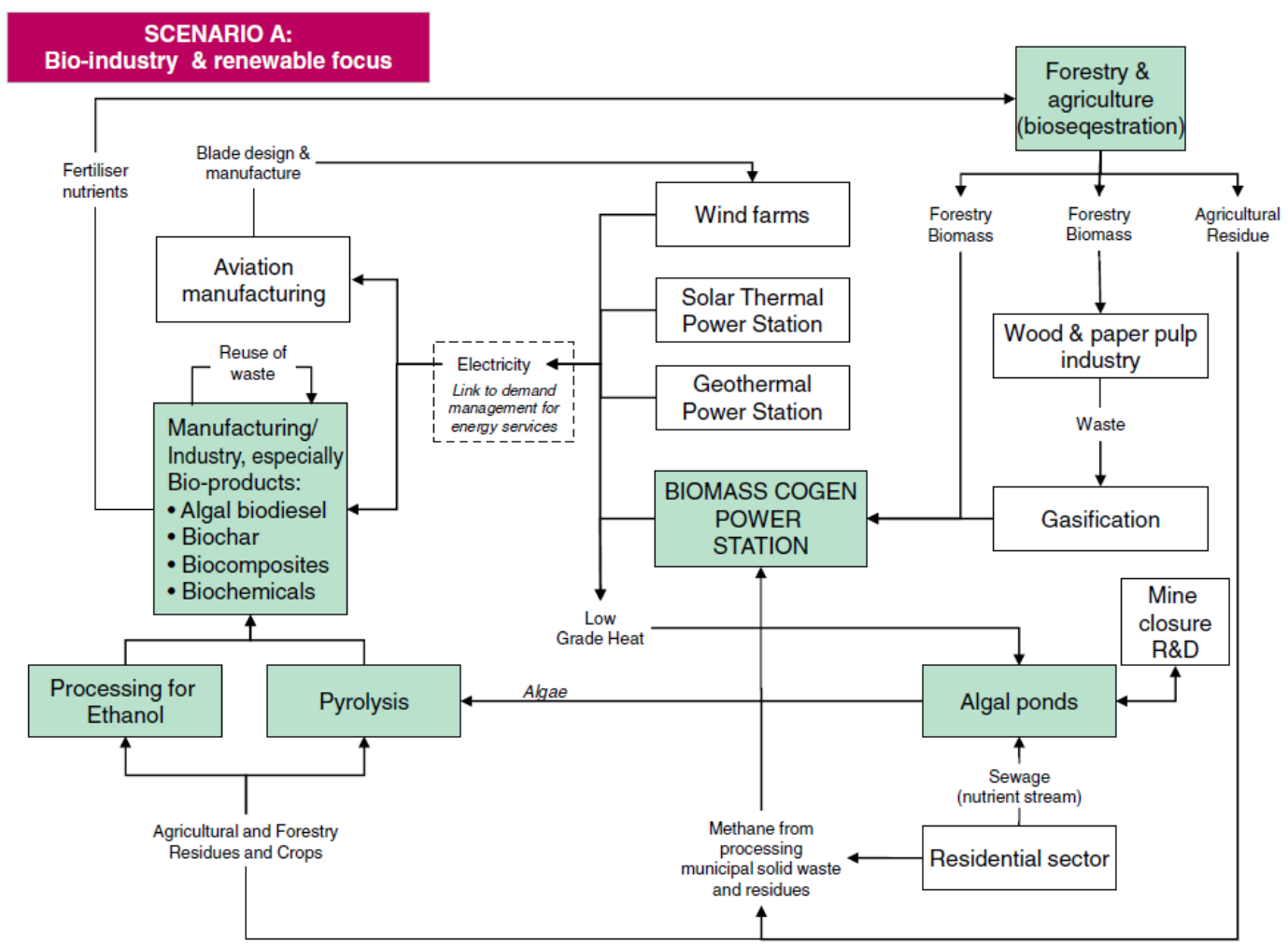

Scenario A is bio-focused, in terms of both energy generation and product perspectives. Other renewable technologies are drawn upon to supplement energy production, including solar, wind and geothermal power.

Existing sectors of forestry and agriculture are enlarged with purpose grown crops. Residues and crops then form inputs into a biomass cogeneration facility (for electricity export to the national grid), pyrolysis for biofuels and biochar, and processing for ethanol production. Some biomass sources could also pass through a gasification stage prior to electricity generation, for improved efficiency of electricity conversion. Other crop residues that are high in moisture content, as well as to food waste from household garbage and stock wastes, can be processed through anaerobic digestion to produce methane for energy generation. The residential sector also provides nutrients (sewage) to be used in intensive cultivation of algae. Low grade heat from electricity generation and any water used for cooling is also used in algae production in ponds which could be in old mine sites - linked to a hub for mine closure research and development.

With such innovative industries, this scenario could also attract yet more new industries to the region. For example, knowledge-based research and development companies may be drawn to the Latrobe Valley, attracted by the opportunity to SUBMITTED UNFORMATTED VERSION to Technological Forecasting and Social Change 2011 78:797-818 
develop and invest in new technologies. The opportunity could exist for the region to become, for example, a hub for renewable energy technology development.

Wind, geothermal and solar systems can produce energy for the region and export surplus electricity to the national grid. Local manufacturing firms can benefit from lower transmission and distribution costs, while the skills that currently exist in the aviation industry could be used to design and manufacture wind turbines.

In addition to this energy production, there is a focus on products. Biodiesel and bioethanol will be manufactured, as will inputs into processes making chemicals, plastics and other composites. Biochar will also be manufactured and used both to sequester carbon and improve soil quality in the region.

\subsubsection{Scenario B - Electricity from coal focus}

The configuration of cluster elements for Scenario B is given in Figure 4.

Figure 4 - Configuration of Scenario B: Energy from Coal focus

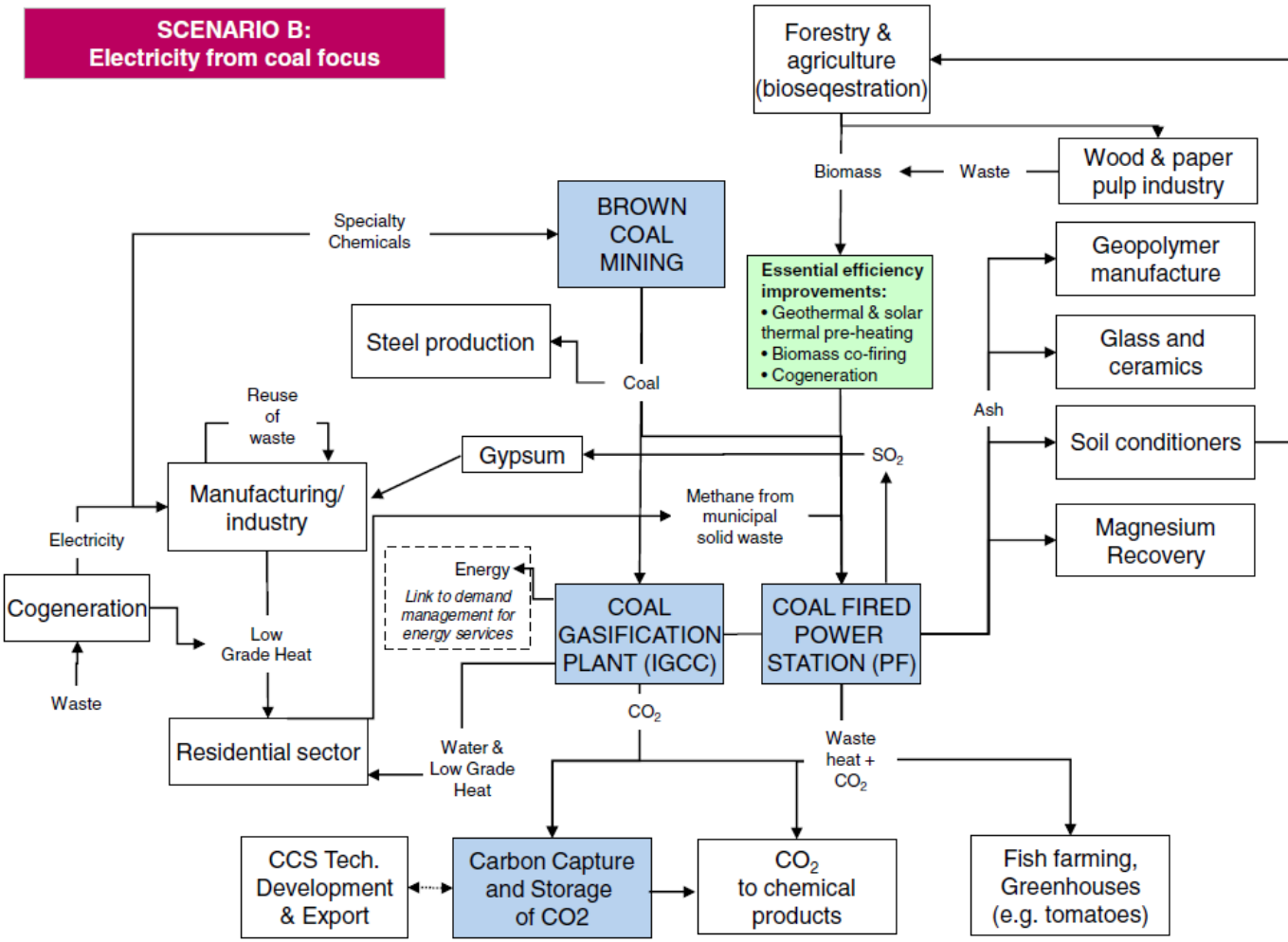

This scenario is based upon coal-fired power generation and is the closest to an extension of the current situation. Here, carbon emissions at some point begin to be captured and stored underground ('CCS'). The scenario also introduces technologies that reduce coal-fired generation greenhouse impacts in the short term, such as solar 
or geothermal preheating. Some carbon dioxide is also used to manufacture chemical products and (with the use of some of the waste heat) crops, such as hydroponic tomatoes. $^{2}$ Strong industrial ecology synergies are made with the use of ash produced as a by-product of the energy generation in an array of products such as glass, ceramics and soil conditioners.

Various forecasts from the Latrobe Valley 2100 (LV2100) report [79] that can be considered similar to Scenario B, although the scale of coal's contribution to the energy mix will differ.

\subsubsection{Scenario $C$ - Coal to products focus}

The cluster configuration for Scenario $\mathrm{C}$ is shown in

Figure 5. This scenario has a focus on the manufacture of products from coal, rather than electricity generation.

Figure 5 - Cluster configuration for Scenario C: Products from coal (nonelectricity)

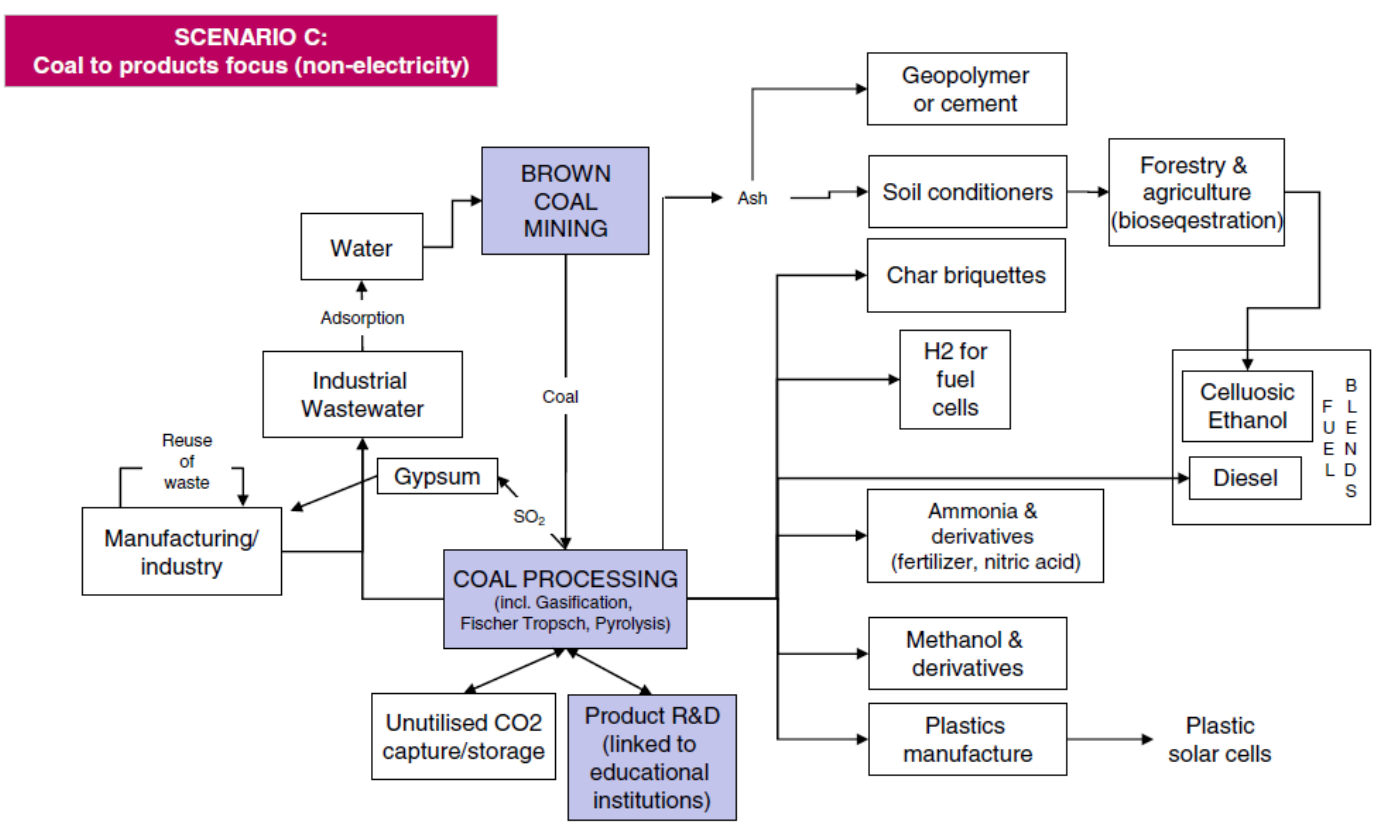

This scenario uses various processes to make a range of products, including hydrogen, ammonia, diesel, methanol, plastics and char briquettes from coal.

\footnotetext{
${ }^{2}$ Note that currently there is a trial of using $\mathrm{CO}_{2}$ to grow algae in the Latrobe Valley, which could also be added to this scenario, see http://www.mbdenergy.com/.
} 
Despite this focus on using coal to create products, the Latrobe Valley will still be the major provider of electrical energy to Victoria. This electricity production is deliberately unspecified and could be achieved through a combination of geothermal, renewable or coal with carbon capture and storage. The motivation for describing this scenario distinctly (and independent of the type of electricity production to which it is linked) is to highlight the different impact and risk profile associated with a coal-toproducts focus.

\subsection{Stage 6: Stakeholder Review and Validation}

The scenarios were presented for review and confirmation by government stakeholders, with respect to the drivers which could lead to such a future and the configuration of interdependent industries. The stakeholders were drawn from the Department of Primary Industries; Department of Sustainability and Environment; and Department of Innovation, Industry \& Regional Development, each of whom had overlapping policy responsibility for the future development of the region. Their inputs at this stage ranged from providing updated policy drivers, to suggestions for individual cluster elements.

\subsection{Stage 7: Scenario Impact Assessment \& Transition Pathways}

This section presents the impact assessment of each scenario. As discussed in the methodology (Section 3), the approach taken for this assessment is broadly based on the “sustainability assessment” type approaches used by Nijkamp and Vreeker [64], but with the additional dimension of considering extraction, processing/usage and disposal life stages. This is a qualitative and semi-quantitative analysis based on expert judgement of relative environmental impacts given the authors' knowledge of the industries and technologies covered.

The use of a life cycle thinking perspective introduces some interesting spatial dimensions to the analysis. In some cases environmental impacts are manifested and need to be managed locally - for example, sulphur dioxide emissions arising from coal based power generation, whereas for exported fuel products such as diesel the 
primary significant impacts occur during use across national borders, necessitating a different strategy for managing impact and responsibility.

The assessment was conducted as follows:

- each stage of each activity was characterised in terms of its degree of impact on the abatement of, or contribution to, greenhouse gas emissions and water use, taken from a life cycle perspective. These impacts are denoted as --/and $+/++$ respectively, in tabular format. That is, a negative contribution in greenhouse gas emissions represents abatement, while a positive contribution represents an emission. Due to scope constraints of the research, only greenhouse and water issues were explicitly considered across every lifecycle stage, although other environmental issues such as particulate air pollution emissions were also noted in the relevant stages.

- brief comments on technical, social and economic considerations were recorded in tabular format

In considering the transition to future scenarios there are different technical and other risks associated with particular technologies. The transitionary considerations have therefore been expressed within this assessment framework as technical, sociopolitical and economic impacts/challenges, and skills and institutional considerations rather than specific transition milestones in a trajectory from the status quo to alternative future.

\subsubsection{Scenario A assessment: Bio-Industry \& Renewable Focus}

Table 3 presents an assessment of the first scenario focussed on bio-industry and renewables. 
Table 3: Scenario A assessment: Bio-industry \& renewable focus

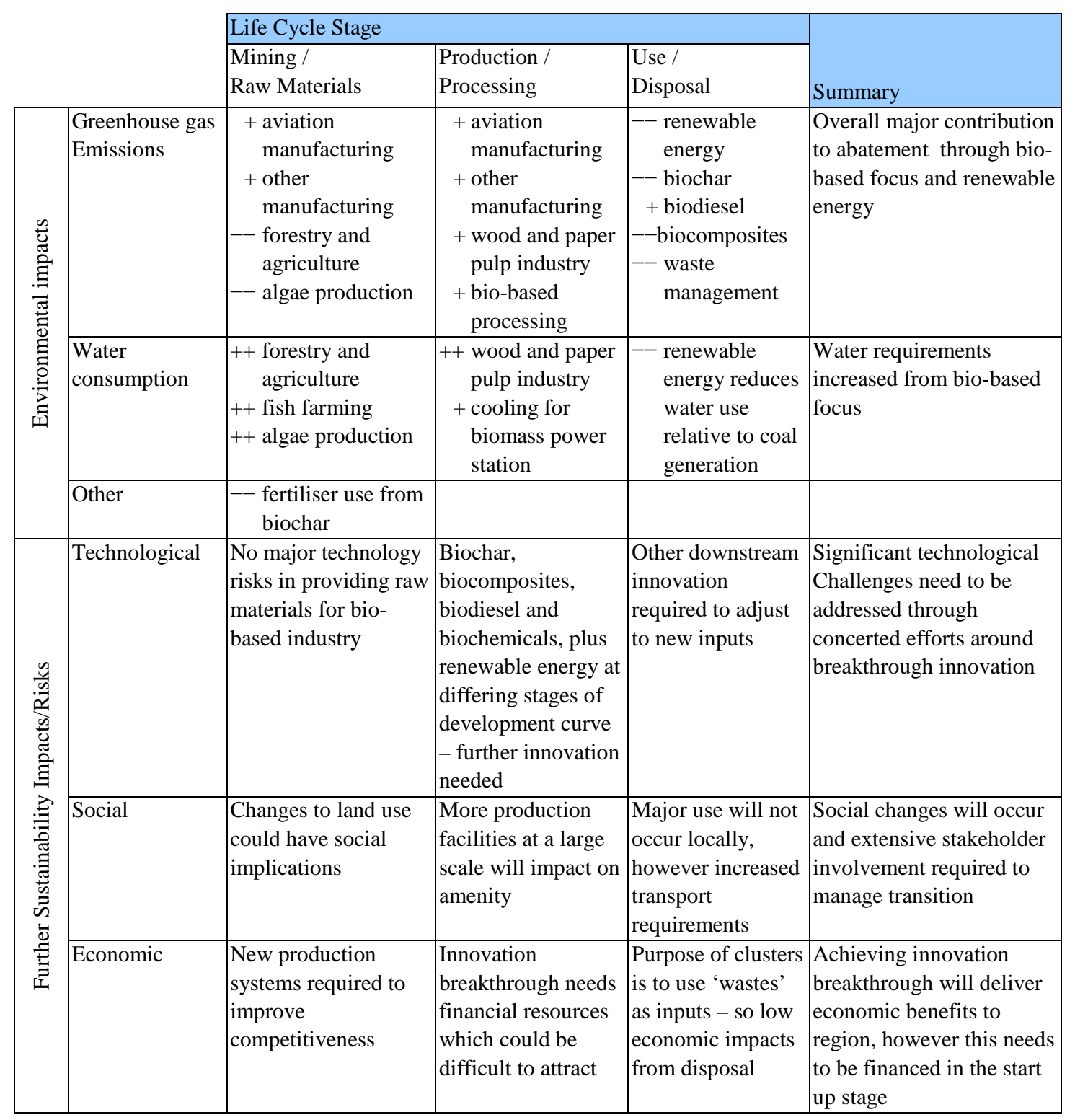

Scenario A makes considerable environmental gains together with economic growth. Under this scenario the region would act as a carbon sink (absorber of carbon) for Victoria, thereby significantly contributing to a no- or low-carbon future. The bio-industry focus does, however, come with increased water requirements. Yet this is compensated to some degree by freeing up of significant water allocations currently used by coal-fired electricity generators. Other environmental benefits outside the scope of these greenhouse and water considerations include soil nourishment through biochar fertilisation. 


\section{Transitioning}

The transition path to this scenario requires a complete shift from the current energy infrastructure, which represents major structural change for the government, industry and community. This would present a significant and deliberate effort to adapt regulatory and market environments to accommodate such a shift in the power sector, although the scale of such a policy challenge is proportional to the rate of change over which the transition is managed. In terms of developing symbiotic transition paths, the forestry and biomass cogeneration facilities would be suitable for early co-development, with algae and biochar industries to follow. Socially, the challenges associated with a move to this scenario are in a transition from the workforce going from a small number of large employers to greater activity at the small-medium enterprise level, providing opportunities for local entrepreneurs with appropriate skills. Extensive stakeholder involvement would be required to manage this transition and to ensure that the community is osupportive of the policy development process. As with other scenarios, some breakthrough technologies are required to get the maximum benefit from this scenario and this could require high levels of investment in research and development.

\subsubsection{Scenario B assessment: Electricity from coal}

Table 4 presents an assessment of the second scenario focussed on electricity from coal. 
Table 4: Scenario B assessment: Electricity from coal

\begin{tabular}{|c|c|c|c|c|c|}
\hline & \multicolumn{3}{|l|}{ Life Cycle Stage } & \multirow[b]{2}{*}{ Summary } \\
\hline & & $\begin{array}{l}\text { Mining / } \\
\text { Raw Materials }\end{array}$ & \begin{tabular}{|l|} 
Production / \\
Processing
\end{tabular} & $\begin{array}{l}\text { Use / } \\
\text { Disposal }\end{array}$ & \\
\hline \multirow{3}{*}{ 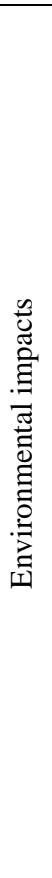 } & GHG Emissions & $\begin{array}{l}+ \text { Brown Coal } \\
\text { mining } \\
\text { - Forestry / } \\
\text { agriculture }\end{array}$ & $\begin{array}{l}++ \text { Coal gasifi- } \\
\text { cation plant } \\
++ \text { Coal fired power } \\
\text { station } \\
++ \text { Cement } \\
\text { manufacture } \\
\text { (+ Geopolymers) } \\
\text { - CO2 to } \\
\text { chemicals } \\
\text { - Solar thermal } \\
\text { pre-heating } \\
\text { - Greenhouses }\end{array}$ & $--\mathrm{CCS}$ & Low overall emissions \\
\hline & $\begin{array}{l}\text { Water } \\
\text { consumption }\end{array}$ & $\begin{array}{l}+ \text { Brown Coal } \\
\text { mining } \\
+ \text { Forestry / } \\
\text { agriculture }\end{array}$ & $\begin{array}{l}++ \text { Coal gasifi- } \\
\text { cation plant } \\
++ \text { Coal fired power } \\
\text { station } \\
+ \text { Paper and pulp } \\
\text { industry } \\
\text { + Greenhouses }\end{array}$ & $\begin{array}{l}\text { - recycling for } \\
\text { residential use } \\
\text { (coming from } \\
\text { IGCC) }\end{array}$ & $\begin{array}{l}\text { Moderate-high water usage, } \\
\text { depends on newer } \\
\text { technology }\end{array}$ \\
\hline & Other & $\begin{array}{c}++ \text { Mined land } \\
\text { impacts }\end{array}$ & \begin{tabular}{|l}
+ \\
$\begin{array}{l}\text { Fly ash, heat, air } \\
\text { emissions }\end{array}$
\end{tabular} & $\begin{array}{l}+ \text { Potential } \\
\text { impacts associated } \\
\text { with } \mathrm{CO}_{2} \text { storage }\end{array}$ & \\
\hline \multirow{3}{*}{ 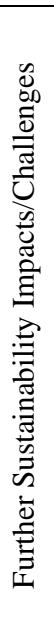 } & Technological & \begin{tabular}{|l|} 
Forestry and \\
agriculture may be \\
adversely impacted by \\
climate change
\end{tabular} & $\begin{array}{l}\mathrm{CO}_{2} \text { to chemicals } \\
\text { and geopolymners } \\
\text { requires further } \\
\text { technological and } \\
\text { market development }\end{array}$ & \begin{tabular}{|l|} 
Development of \\
CCS as long term \\
solution subject to \\
technical risk
\end{tabular} & $\begin{array}{l}\text { Requires technological } \\
\text { breakthroughs- potential to } \\
\text { export CCS know-how and } \\
\text { technology overseas }\end{array}$ \\
\hline & Socio-political & \begin{tabular}{|l} 
Potential for backlash \\
both against continued \\
mining and mine \\
closure [80]
\end{tabular} & \begin{tabular}{|l|} 
Coal fired power \\
subject to future \\
regulation nationally \\
/ internationally
\end{tabular} & \begin{tabular}{|l|} 
Public acceptance \\
of CCS and \\
required licence to \\
operate
\end{tabular} & $\begin{array}{l}\text { Potential to extend from } \\
\text { status quo }\end{array}$ \\
\hline & Economic & $\begin{array}{l}\text { Coal price may } \\
\text { change }\end{array}$ & $\begin{array}{l}\text { Potential that other } \\
\text { forms of energy } \\
\text { (e.g. distributed) are } \\
\text { more cost- } \\
\text { competitive in a } \\
\text { carbon constrained } \\
\text { environment }\end{array}$ & \begin{tabular}{|l|} 
Carbon price \\
affects \\
competitiveness of \\
CCS and \\
technology \\
development is \\
capital intensive
\end{tabular} & $\begin{array}{l}\text { Technology development is } \\
\text { capital intensive - other } \\
\text { options may be cheaper }\end{array}$ \\
\hline
\end{tabular}

Environmental impacts for this scenario occur largely within the Latrobe Valley. However, if the carbon capture and storage (CCS) technology developed under this scenario is exported, then the benefits of reduced greenhouse impacts would indirectly extend out of the region. Additionally, as current CCS trials are located in the Otway Basin [80], several hundred kilometres from Latrobe, there are likely to be environmental impacts associated with $\mathrm{CO}_{2}$ storage outside the Latrobe region.

As noted, the scenario offers possibilities to introduce technologies that reduce impacts in the short term, such as solar or geothermal preheating, as well as the longer term through CCS. The scenario involves significant greenhouse impacts in the 
mining and processing stages, but this is compensated by the use of CCS technology, which would enable lower end-of-pipe emissions.

Regarding water, the mining and production stages involve significant consumption, which is only compensated in a minor way by some water recycling in the residential sector. The overall life cycle outcome was considered 'moderate-high' relative to the bio industries scenario, which was rated as 'high' in this regard.

Other negative environmental impacts include particulate and other emissions from the mining and processing stages.

\section{Transitioning}

The principal risk for this scenario is the technological risk associated with CCS becoming cost-competitive and large-scale storage areas being located. As this scenario is an extension of the current situation, less structural adjustment would be required in the transition, likely resulting in more favourable industry perceptions. Regarding transition pathways to strengthen symbiotic relationships, selected industries using ash (e.g. geopolymers, glass) and also waste heat from coal fired power (e.g. fish farming, greenhouse tomato cultivation) could be developed earlier to build on existing infrastructure. Then, further infrastructure to support large-scale CCS would need to be developed, particularly with regard to connecting coal plants with CCS technology to storage locations. Such infrastructure-intensive developments imply high levels of required investment. While a major benefit of this scenario is in positioning the region and Australia as a leader in the development of CCS technology, the labour pool will require the necessary technical research and development skills to realise this outcome, which is a significant transitionary consideration. The potential overseas market is considerable as long as coal-based power generation remains a major energy source overseas. Additionally, some of the technologies presented require further technological and market development, which would require dedicated policy and funding support.

Socially, as this scenario is the closest to an extension of business as usual, there is expected to be fewer transitionary issues, although the public perception of CCS throughout the development phase may need to be carefully managed for a future so heavily reliant on one technology. 


\subsubsection{Scenario $C$ assessment: Coal to products}

Table 5 presents an assessment of the third scenario focussed on coal to products (with unspecified mix for energy provision).

Table 5: Scenario C assessment: Coal to products

\begin{tabular}{|c|c|c|c|c|c|}
\hline & \multicolumn{3}{|l|}{ Life Cycle Stage } & \multirow[b]{2}{*}{ Summary } \\
\hline & & \begin{tabular}{|l|} 
Mining / \\
Raw Materials
\end{tabular} & \begin{tabular}{|l|} 
Production / \\
Processing
\end{tabular} & $\begin{array}{l}\text { Use / } \\
\text { Disposal }\end{array}$ & \\
\hline \multirow{3}{*}{ 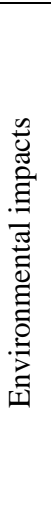 } & GHG Emissions & $\begin{array}{l}+ \text { Brown Coal } \\
\text { mining }\end{array}$ & $\begin{array}{l}\text { + Coal processing } \\
+ \text { Geopolymers } \\
\text { (or }++ \text { if cement } \\
\text { manufacture) } \\
+ \text { Plastics } \\
\text { manufacture }\end{array}$ & $\begin{array}{l}\text { - CCS } \\
+ \text { Char briquettes } \\
+ \text { When diesel } \\
\quad \text { combusted }\end{array}$ & $\begin{array}{l}\text { Product focus has additional } \\
\text { emissions associated with } \\
\text { production and transport. } \\
\text { Primary impacts are outside } \\
\text { the region }\end{array}$ \\
\hline & $\begin{array}{l}\text { Water } \\
\text { consumption }\end{array}$ & $\begin{array}{l}+ \text { Brown Coal } \\
\text { mining }\end{array}$ & + Coal processing & $\begin{array}{l}\text { when } \mathrm{H}_{2} \text { used } \\
\text { in fuel cells } \\
\text { (inside or } \\
\text { outside } \\
\text { Latrobe) }\end{array}$ & Moderate water usage \\
\hline & Other & $\begin{array}{c}++ \text { Mined land } \\
\text { impacts }\end{array}$ & + Ash emissions & $\begin{array}{l}+ \text { Impacts of } \\
\text { fertilizer, plastics }\end{array}$ & \\
\hline \multirow{3}{*}{ 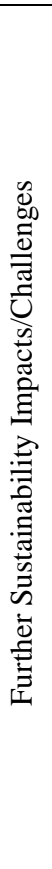 } & Technological & $\begin{array}{l}\text { Forestry and } \\
\text { agriculture may be } \\
\text { adversely impacted by } \\
\text { climate change }\end{array}$ & $\begin{array}{l}\text { Additional } \\
\text { technology } \\
\text { development } \\
\text { required (R\&D) for } \\
\text { coal to products } \\
\text { Complex cluster } \\
\text { arrangement. }\end{array}$ & \begin{tabular}{|l|} 
Development of \\
CCS as long term \\
solution subject to \\
technical risk \\
Risk associated \\
with hydrogen \\
economy \\
development
\end{tabular} & $\begin{array}{l}\text { Diverse new technology } \\
\text { required }\end{array}$ \\
\hline & Socio-political & $\begin{array}{l}\text { Potential for backlash } \\
\text { both against continued } \\
\text { mining and mine } \\
\text { closure [80] }\end{array}$ & $\begin{array}{l}\text { Requires shift in } \\
\text { focus for regional } \\
\text { production, with } \\
\text { associated logistics } \\
\text { upgrades to export } \\
\text { products. } \\
\text { Energy mix can } \\
\text { vary. }\end{array}$ & $\begin{array}{l}\text { Products have } \\
\text { impacts when } \\
\text { used (external to } \\
\text { Latrobe valley), } \\
\text { alters risk profile } \\
\text { of scenario }\end{array}$ & $\begin{array}{l}\text { Requires active cluster } \\
\text { development }\end{array}$ \\
\hline & Economic & $\begin{array}{l}\text { Price for raw material } \\
\text { inputs must be } \\
\text { competitive }\end{array}$ & $\begin{array}{l}\text { Leading coal to } \\
\text { products } \\
\text { technologies } \\
\text { currently in } \\
\text { development } \\
\text { overseas }\end{array}$ & $\begin{array}{l}\text { Market potential } \\
\text { will be influence } \\
\text { by oil availability } \\
\text { and } \\
\text { competitiveness of } \\
\text { products }\end{array}$ & Products market may vary \\
\hline
\end{tabular}

Impacts in this scenario occur both within and outside Latrobe, especially in products that are exported and may be used elsewhere, such as diesel. Actual impacts will also depend on the source of electricity generation for this scenario, which was not specified in the development of the scenario (see Section 4.6.3). 
The product focus results in emissions associated with both production and transport. This scenario requires CCS to be working effectively to cope with any remaining carbon dioxide from the product manufacture stage.

Regarding water consumption, impacts were considered moderate ('+') at all life cycle stages. This is the best performer with respect to water consumption of the three scenarios considered, although does not consider the electricity source for this scenario as part of the assessment in the assessment. If coal with CCS were the primary energy source, this would increase water consumption.

As coal usage is high to very high in this scenario (Figure 2), the mined land impacts are significant, while other impacts such as fertiliser and ash emissions are moderate.

\section{Transitioning}

The industrial symbiosis that occurs between the cluster companies in this scenario is tightly linked and interdependent. The 'anchor-tenant' in this scenario is clearly coal processing (including pyrolysis, gasification,) and would need to be developed early in the transition path. With a strong product focus, technology development (R\&D) for coal to products will also be important, as will transport infrastructure upgrades to move products quickly and efficiently. Both these factors require strong investment. External influences are difficult to predict, but they could have big implications for the market in this scenario. Influences could include the declining supply of oil or the size of any future economy based around hydrogen as an energy carrier. The same social and infrastructure transitionary considerations as Scenario B apply to this scenario with respect to reliance on CCS.

\subsection{Discussion of case study results}

Short- and long-term drivers are affecting the Latrobe Valley with increasing momentum. Climate change, carbon trading and the push for carbon neutrality will affect the way the region does business in the future. In addition, uncertainty about how regulation, technology and social attitudes will change means that Latrobe must consider a variety of options to steer it towards a prosperous future. 
Localised industrial symbiosis has proven successful in the minerals industry [81] and could provide the mechanism required to navigate these uncertainties. Rather than ensuring flexibility per se, they enable industrial diversification, technological innovation, environmental benefits and increased investment, and can prompt a required shift to integrated service provision for a sustainable economy.

With its abundant natural resources and potential for utility sharing, the Latrobe Valley is in a strong position to develop clusters to ensure its future prosperity and ability to adapt to an uncertain and challenging future. Water scarcity could provide the initial stimulus which encourages organisations to collaborate. The region also faces constraints. It currently has a narrow industry base which could result in an over-reliance on a few organisations and a relatively low-skilled labour pool which may restrict its ability to innovate and adapt to new industries and technologies. In addition, it currently lacks a hub of innovation and a co-ordinating body.

A summary of the three potential scenarios explored as part of this study, along with the likely impacts of following these paths is presented in Figure 6.

Figure 6: Summary of impacts for scenarios

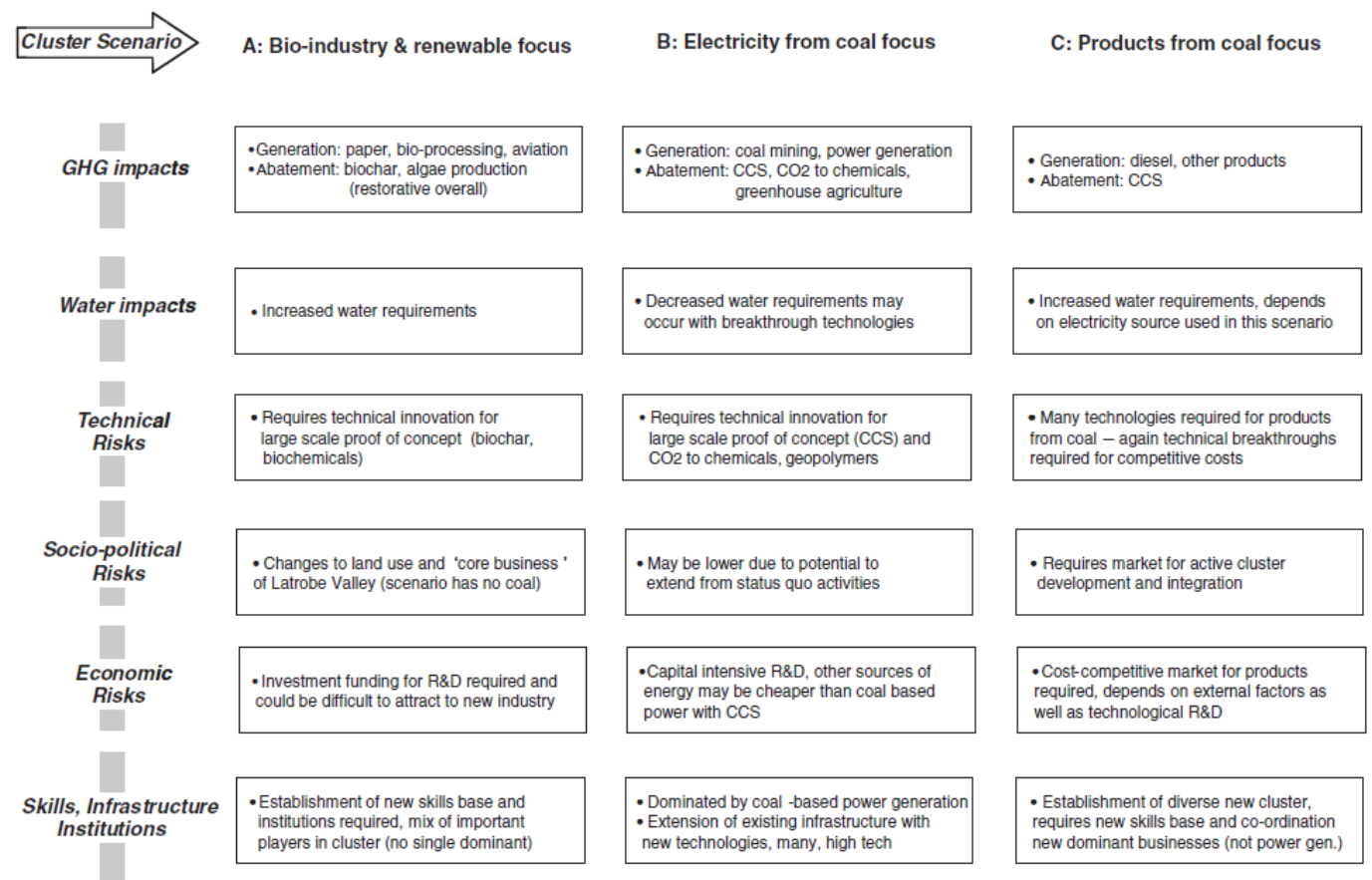


Each of the scenarios has a combination of positive and negative impacts, and it would be most effective if a transparent stakeholder engagement process with government, industry and civil society were initiated the Latrobe Valley to assess the relative costs and benefits of different clusters and deliberate on a preferred future and strategies to initiate and support cluster development. In the absence of such a process, the future may be determined by a mix of policy incentives and technological innovations. For example, the degree of financial support governments give to the development of CCS may lead to a perception that the solution is at hand and slow the uptate of renewable technologies. As decommissioning of ageing existing coal fired

power stations occurs in the coming decade, the replacement technology chosen could have a big influence on the direction of future scenario development.

\section{CONCLUDING REFLECTIONS}

This paper draws the following conclusions:

- the methodology developed in this paper to combine industrial ecology and backcasting leads to new a creativity in developing future scenarios and transition paths by using the ecological metaphor as a bridge to connect global and local drivers, technology elements and available local resources.

- there is significatn merit in developing distinct, mostly non-overlapping scenarios linked to a central vision. These scenarios provide representations used to illustrate future possibility as well as barriers and opportunities assocaited with transiton pathways.

- the life cycle thinking approach is useful to combine with the industrial ecology-based scenarios to give explicit consideration to which impacts will need to be managed locally and which are managed outside the region.

- whilst it was not possible to undertake a deliberative engagement process with the community on a preferred future within the current study, the research presented here contributed to stakeholder learning by policymakers and will inform future approaches to policy development [82]. Further, the reserach developed a methodology to link industrial ecology based backcasting with a life cycle thinking approach to sustainability assessment.

A generic process for using the work in this paper as the basis for a wider, more participatory backcasting exercise is illustrated in Figure 8. 
Figure 8: Process for using backcast scenarios as input to preferred future
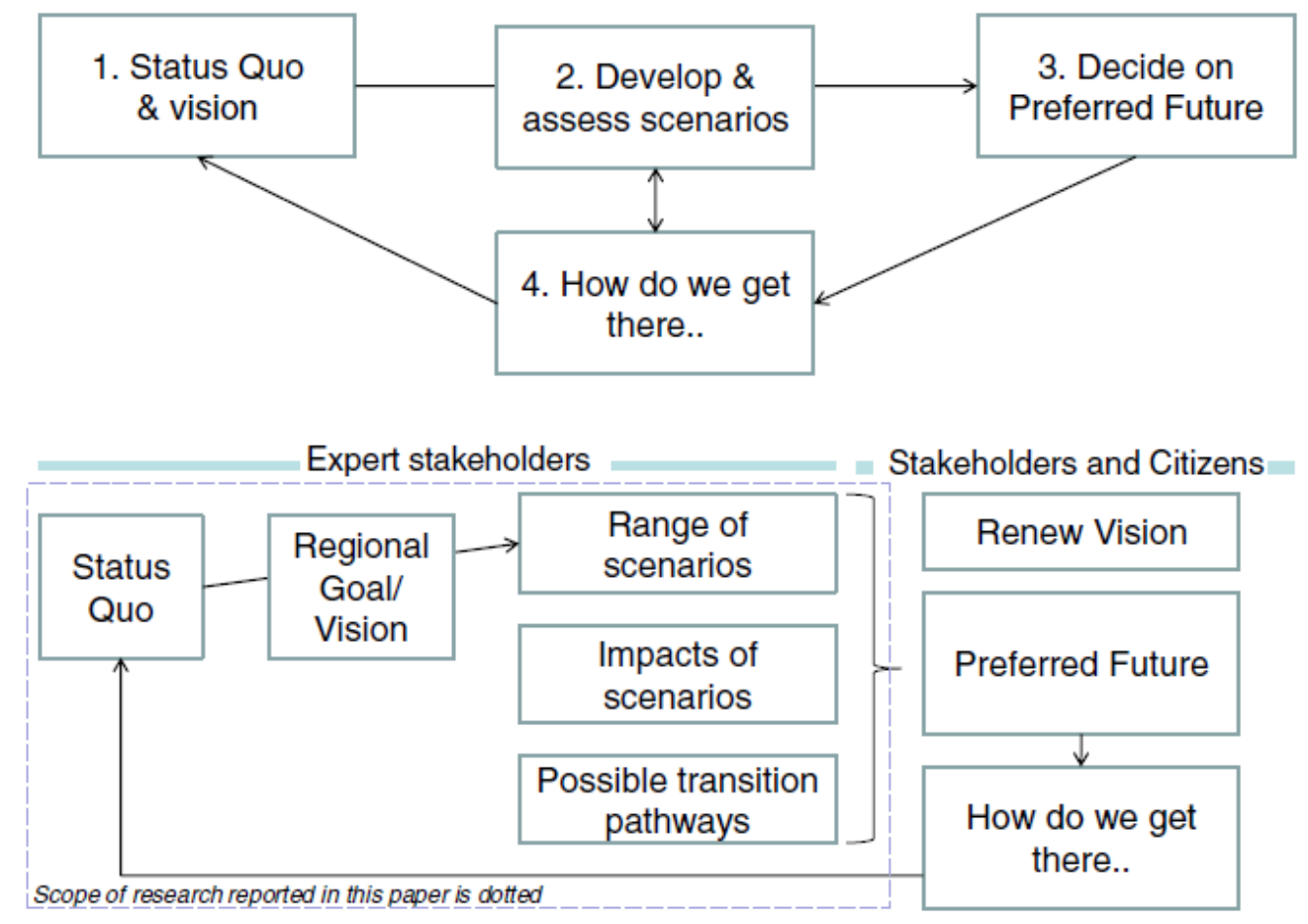

Figure 8 shows that the alternative futures generated in this work as providing tangible configurations of resource and industry linkages in the future, together with insights into the environmental, technical, economic and socio-political impact profile of each. This can provide a bridge for understanding the potential and challenges associated with alternative futures and the useful role industrial symbiosis could play in supporting transition from which a preferred vision can be constructed.

Reflecting on the methodology used in this research, the focus was on developing scenarios and potential transition paths, as input to a second phase (yet to be undertaken) to develop a broader vision involving citizens and wider stakeholders. In this way, the method developed in this project could be described as 'iterative backcasting', which represents a variant of 'second-order backcasting' described by Robinson [4]. Such a method, would compare backcast scenarios against goals and objectives established outside the analysis as part of a larger participatory backasting process. Thus the backcasting process is itself designed as part of the stakeholder engagement process, to open discussion about preferred futures rather than arrive at a preferred future in a single iteration. In our iterative backcasting, the initial detail in both environmental assessment and transition obstacles, frames the risk and benefit 
profile of each scenario as input to a preferred future developed through participatory means.

The other key element of this approach was to use industrial ecology as the basis for the development of alternative futures for a geographic region. This was beneficial in that it prompted consideration of resource loops, and at the scale at which they should be closed. Hence, regarding the appropriateness of the industrial ecology metaphor for use in backcasting - for stimulating creative possibility its usefulness is strong. Regarding implementation pathways for industrial ecology-based scenarios, the top down approach of government-lead planning of industrial ecology development has shown to be less useful that that which emerges on its own [78], however there is potential for industrial symbiosis to strengthen the emergence of a new industrial base. Seeking to apply industrial ecology principles to the backcasting of a product based industrial ecology would offer new challenges in working across spatial scales.

In relation to future development of the impact assessment process, further work should also consider an expanded sustainability assessment including carbon property rights[32], and water access and rights as these are areas of emerging development and possible constraints. Building on the work of Hooker and Brinsmead [83] to incorporate an assessment of the adaptability and resilience of alternative futures is also worthy of further research. Ultimately, the overall approach should be developed to support Strategic Sustainable Development [2].

\section{ACKNOWLEDGEMENTS}

This work was funded by the Department of Primary Industries, Victoria (Australia) and special thanks go to Renee Kjar and Sean Rooney for their support of the study and valuable comments. The authors also wish to thank James Lewis, Institute for Sustainable Futures at the University of Technology, Sydney for his work on this project; and Jaco Quist and Philip Vergragt and other anonymous reviewers for their constructive comments on this paper. 


\section{REFERENCES}

[1] J. Robinson, Futures under glass: A recipe for people who hate to predict, Futures, 22 (1990) 820-842.

[2] K.-H. Robèrt, B. Schmidt-Bliik, J. Aloisi de Larderel, G. Basile, J. Jansen, R. Kuehr, P. Price Thomas, M. Suzuki, P. Hawken, M. Wackernagel, Strategic sustainable development - selection, design and synergies of applied tools., Journal of Cleaner Production, 10 (2002) 197-214.

[3] J. Robinson, Unlearning and backcasting: rethinking some of the questions we ask about the future, Technological Forecasting and Social Change, 33 (1988) 325-388.

[4] J. Robinson, Future subjunctive: backcasting as social learning, Futures, 35 (2003) 839-856.

[5] K. Dreborg, Essence of backcasting, Futures, 28 (1996) 813-828.

[6] J. Korhonen, Industrial ecology in the strategic sustainable development model: strategic applications of industrial ecology, Journal of Cleaner Production, 12 (2004) 809-823.

[7] P.P.-J. Yang, O.B. Lay, Applying ecosystem concepts to the planning of industrial areas: a case study of Singapore's Jurong Island, Journal of Cleaner Production, 12 (2004) 10111023.

[8] K. Green, C. Foster, Give peas a chance: Transformations in food consumption and production systems, Technological Forecasting and Social Change, 72 (2005) 663-679.

[9] P.J. Partidario, J. Vergragt, Planning of strategic innovation aimed at environmental sustainability: actor-networks, scenario acceptance and backcasting analysis within a polymeric coating chain, Futures, 34 (2002) 841-861.

[10] P. Deutz, D. Gibbs, Industrial ecology and regional development: eco-industrial development as cluster policy, Regional Studies, 42 (2008) 1313-1328.

[11] K. Anderson, Reconciling the electricity industry with sustainable development: backcasting - a strategic alternative, Futures, 33 (2001) 607-623.

[12] H. Mulder, W. Biesiot, Transition to a sustainable society- a backcasting approach to modelling energy and ecology., Edward Elgar, Cheltenham, UK, 1998.

[13] K.-H. Robèrt, Tools and concepts for sustainable development, how do they relate to a general framework for sustainable development, and to each other?, Journal of Cleaner Production, 8 (2000) 243-254.

[14] J. Robinson, Energy backcasting: a proposed method of policy analysis, Energy policy, 10 (1982) 337-344.

[15] A.L. Porter, W.B. Ashton, G. Clar, J.F. Coates, K. Chuhls, S.W. Cunningham, K. Duchatel, P. van der Duin, L. Georgehiou, T. Gordon, H. Lindstone, V. Marchau, G. Massari, I. Miles, M. Mogee, A. Salo, F. Scapolo, R. Smits, W. Thissen, Technology futures analysis: Toward integration of the field and new methods, Technological Forecasting and Social Change, 71 (2004) 287-303.

[16] F. Berkhout, Technological regimes, path dependency and the environment, Global environmental change, 12 (2002) 1-4.

[17] J. Quist, P. Vergragt, Past and future of backcasting: The shift to stakeholder participation and a proposal for a methodological framework, Futures, 38 (2006) 1027-1045.

[18] A. Lovins, Energy strategy: the road not taken, Foreign Aff., 55 (1976) 65.

[19] J.N. Swisher, G. de Martino Jannuzzi, R.Y. Redlinger, Tools and methods for integrated resources plannning: improving energy efficiency and protecting the environment, in, UNEP Collaborating Centre on Energy and Environment, Denmark, 1997.

[20] S. White, S.A. Fane, D. Giurco, A.J. Turner, Putting the economics in its place: decisionmaking in an uncertain environment, in: C. Zografos, R. Howarth (Eds.) Deliberative Ecological Economics, Oxford University Press, New Dehli, India, 2008, pp. 80-106.

[21] A. Turner, J. Willets, S. Fane, D. Giurco, A. Kazaglis, S. White, Guide to demand management, Water Services Association of Australia, Sydney, 2008.

[22] M. Höjer, L. Mattsson, Determinism and backcasting in future studies, Futures, 32 (2000) 613-634. 
[23] A. Carlsson-Kanyama, K.H. Dreborg, H.C. Moll, D. Padovan, Participative backcasting: A tool for involving stakeholders in local sustainability planning, Futures, 40 (2008) 34-46.

[24] R. Frosch, N. Gallopoulos, Strategies for manufacturing, Scientific American, 261 (1989) 144-152.

[25] J. Ehrenfeld, Putting a spotlight on metaphors and analogies in industrial ecology, Journal of Industrial Ecology, 7 (2003) 1-4.

[26] J. Spiegelman, Beyond the food web: connections to a deeper industrial ecology, Journal of Industrial Ecology, 7 (2003) 17-23.

[27] R. Lifset, T. Graedel, Industrial ecology: Goals and definitions, A handbook of industrial ecology, (2002) 3-15.

[28] J. Korhonen, Two paths to industrial ecology: applying the product-based and geographical approaches, Journal of Environmental Planning and Management, 45 (2002) 39-57.

[29] R. Ayres, L. Ayres, Industrial ecology: Towards closing the materials cycle, Edward Elgar, Cheltenham, 1996.

[30] R. van Berkel, M. Lafleur, Application of an industrial ecology toolbox for the introduction of industrial ecology in enterprises--II, Journal of Cleaner Production, 5 (1997) 27-37.

[31] J. Sarkis, A strategic decision framework for green supply chain management, Journal of Cleaner Production, 11 (2003) 397-409.

[32] D. Giurco, J. Prior, S. Boydell, Industrial Ecology and Carbon Property Rights: Future Scenarios in the Latrobe Valley, Australia Journal of Industrial Ecology, (submitted).

[33] B.H. Roberts, The application of industrial ecology principles and planning guidelines for the development of eco-industrial parks: an Australian case study, Journal of Cleaner Production, 12 (2004) 997-1010.

[34] D. Gibbs, P. Deutz, Reflections on implementing industrial ecology through eco-industrial park development, Journal of Cleaner Production, 15 (2007) 1683-1695.

[35] H. Shi, Industrial ecology in China, part 1, Journal of Industrial Ecology, 6 (2008) 7-11.

[36] H. Shi, M. Chertow, Y. Song, Developing country experience with eco-industrial parks: a case study of the Tianjin Economic-Technological Development Area in China, Journal of Cleaner Production, 18 (2010) 191-199.

[37] T. Tudor, E. Adam, M. Bates, Drivers and Limitations for the successful Development and functioning of EIPs (Eco-industrial Parks): a Literature Review, Ecological Economics, 61 (2007) 199-207.

[38] M. Chertow, Industrial Symbosis: Literature and Taxonomy, Annual review of energy and the environment, 25 (2000) 313-337.

[39] A. Garner, G.A. Keolian, Industrial Ecology - an introduction. Cited in Goyal, S., Nema, P., and Devotta, S. Sustainable Industrial Development and Environment Protection: an emerging perspective, Environmental Progress, 27 (1995) 58-65.

[40] D. Gibbs, Ecological modernisation, regional economic development and regional development agencies, Geoforum, 31 (2000) 9-19.

[41] T. Potts, The natural advantage of regions: linking sustainability, innovation, and regional development in Australia, Journal of Cleaner Production, 18 (2010) 713-725.

[42] C. Andrews, Putting Industrial Ecology into Place Evolving Roles for Planners, Journal of the American Planning Association, 65 (1999) 364-375.

[43] O. Helmer, Looking forward - a guide to futures research, Sage, Beverly Hills, 1983.

[44] M. Porter, Competitive advantage, agglomeration economies, and regional policy, International regional science review, 19 (1996) 85.

[45] B. Roberts, M. Enright, Industry clusters in Australia: recent trends and prospects, European Planning Studies, 12 (2004) 99-121.

[46] R. Côté, E. Cohen-Rosenthal, Designing eco-industrial parks: a synthesis of some experiences, Journal of Cleaner Production, 6 (1998) 181-188.

[47] J. Ehrenfeld, N. Gertler, Industrial ecology in practice, J. Industrial Ecology, 1 (1997) 6779. 
[48] R. van Berkel, Eco-efficiency in the Australian minerals processing sector, Journal of Cleaner Production, 15 (2007) 772-781.

[49] P. Berkhout, J. Muskens, Defining the rebound effect, Energy Policy, 28 (2000) 425-432.

[50] C. Hardy, T. Graedel, Industrial ecosystems as food webs, Journal of Industrial Ecology, 6 (2002) 29-37.

[51] D. van Beers, A. Bossilkov, R. van Berkel, A Regional Synergy Approach to Advance Sustainable Water Use: A Case Study Using Kwinana (Western Australia), Australasian Journal of Environmental Management, 15 (2008) 149.

[52] R. van Berkel, Regional Resource Synergies for Sustainable Development in Heavy Industrial Areas: An Overview of Opportunities and Experiences. , in, Perth, Australia: Curtin University of Technology, 2006.

[53] Kalundborg Centre for Industrial Symbiosis, Industrial Symbiosis, in, 2007.

[54] N. Jacobsen, Industrial symbiosis in Kalundborg, Denmark: A quantitative assessment of economic and environmental aspects, Journal of Industrial Ecology, 10 (2008) 239-255.

[55] H.-L. Pesonen, T. Ekvall, G. Fleischer, G. Huppes, C. Jahn, Z. Klos, G. Rebitzer, G. Sonnemann, A. Tintinelli, B. Weidema, H. Wenzel, Framework for Scenario Development in LCA, International Journal of Life Cycle Assessment, 5 (2000) 21-30.

[56] Y. Fukushima, M. Hirao, A structured framework and language for scenario-based life cycle assessment, International Journal of Life Cycle Assessment, 7 (2002) 317-329.

[57] T. Graedel, Streamlined Life-Cycle Assessment, Prentice Hall, Englewood Cliffs, 1998.

[58] W. Sheate, M. Partidario, H. Byron, O. Bina, S. Dagg, Sustainability assessment of future scenarios: methodology and application to mountain areas of Europe, Environmental management, 41 (2008) 282-299.

[59] J. Glasson, R. Therivel, A. Chadwick, Introduction to environmental impact assessment, Spon Pr, 2005.

[60] G. Finnveden, M. Nilsson, J. Johansson, Å. Persson, Å. Moberg, T. Carlsson, Strategic environmental assessment methodologies - applications within the energy sector, Environmental impact assessment review, 23 (2003) 91-123.

[61] A. Chaker, K. El-Fadl, L. Chamas, B. Hatjian, A review of strategic environmental assessment in 12 selected countries, Environmental impact assessment review, 26 (2006) $15-56$.

[62] M.R. Partidário, Strategic environmental assessment: Key issues emerging from recent practice, Environmental impact assessment review, 16 (1996) 31-55.

[63] J. Pope, D. Annandale, A. Morrison-Saunders, Conceptualising sustainability assessment, Environmental impact assessment review, 24 (2004) 595-616.

[64] P. Nijkamp, R. Vreeker, Sustainability assessment of development scenarios: methodology and application to Thailand, Ecological Economics, 33 (2000) 7-27.

[65] P.J. Dortmans, Forecasting, backcasting, migration landscapes and strategic planning maps, Futures, 37 (2005) 273-285.

[66] Latrobe City, Latrobe 2021 - The Vision for Latrobe Valley, in, Report by Latrobe City,, 2006.

[67] Latrobe City, Revised Economic Development Strategy For Latrobe City 2004 - 2008, in, Report by Latrobe City, revised February 2007, 2007.

[68] G. Evans, A just transition from coal to renewable energy in the Hunter Valley of New South Wales, Australia, International Journal of Environment, Workplace and Employment, 3 (2007) 175-194.

[69] Australian Greenhouse Office, Living with climate change: an overview of potential climate change impacts on Australia, in, Australian Greenhouse Office, Canberra, 2002.

[70] D. Sadler, Cluster Evolution, the Transformation of Old Industrial Regions and the Steel Industry Supply Chain in North East England, Regional Studies, 38 (2004) 55-66.

[71] Commonwealth of Australia, Securing Australia's energy future, in, Department of Prime Minister and Cabinet, 2004.

[72] C. Dunstan, J. Daly, Institutional barriers to intelligent grid, in, Institute for Sustainable Futures, UTS, Sydney, 2009. 
[73] Orange. PCS, The way to work: An Orange Future Enterprise coalition report Space, place and technology in 2016, (2006).

[74] MBAC Consulting, The Timber Industry in Gippsland: a Socio-economic assessment, in, The Gippsland Private Forestry Inc. (GPF), Victoria, 2005.

[75] Essential Economics, Latrobe Economic Study - Analysis of Population and Household Growth Potential, in, Report prepared for Latrobe City, 2006.

[76] NEMMCO, Potential Drought Impact on Electricity Supplies in the NEM, in, National Electricity Market Managemet Company Limited, 2007.

[77] D. Giurco, M. Warnken, J. Lewis, E. Langham, B. Cohen, Latrobe Valley Resources Vision: Future developments for business clusters, in, Report prepared by the Institute for Sustainable Futures, UTS and Warnken ISE for the Department of Primary Industries, Melbourne., 2007.

[78] R.R. Heeres, W.J.V. Vermeulen, F.B. de Walle, Eco-industrial park initiatives in the USA and the Netherlands: first lessons, Journal of Cleaner Production, 12 (2004) 985-995.

[79] GHD, Latrobe Valley 2100 Coal Resource Project., in, Report prepared for the Department of Primary Industries, Victoria., 2005.

[80] S. Sharma, P. Cook, T. Berly, M. Lees, The CO2CRC Otway Project: Overcoming challenges from planning to execution of Australia's first CCS project, Energy Procedia, 1 (2009) 1965-1972.

[81] D. van Beers, G.D. Corder, A. Bossilkov, R. van Berkel, Regional synergies in the Australian minerals industry: Case-studies and enabling tools, Minerals Engineering, 20 (2007) 830-841.

[82] R. Kjar, Acting Manager Coal Development, Department of Primary Industries, Victoria, $(27 / 8 / 2010)$.

[83] C. Hooker, T. Brinsmead, Sustainability dimensions and impacts, in, Cooperative Research Centre for Coal in Sustainable Development, 2006. 